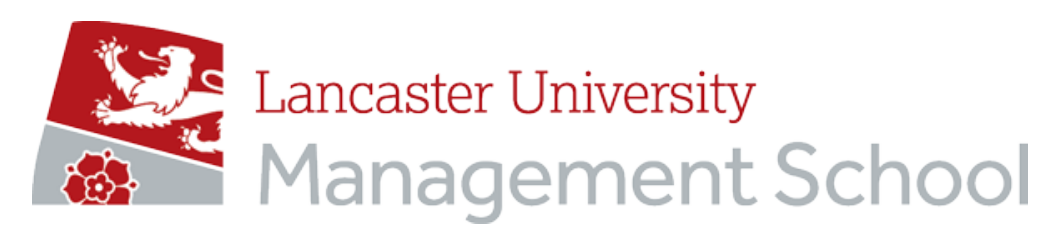

\author{
Economics Working Paper Series
}

2018/021

\title{
Raising Capital from Heterogeneous Investors
}

\author{
Marina Halac, Ilan Kremer and Eyal Winter
}

The Department of Economics

Lancaster University Management School

Lancaster LA1 4YX

$\mathrm{UK}$

(C) Authors

All rights reserved. Short sections of text, not to exceed two paragraphs, may be quoted without explicit permission, provided that full acknowledgement is given. 


\title{
Raising Capital from Heterogeneous Investors*
}

\author{
Marina Halac ${ }^{\dagger} \quad$ Ilan Kremer ${ }^{\ddagger} \quad$ Eyal Winter ${ }^{\S}$ \\ September 5, 2018
}

\begin{abstract}
A firm raises capital from multiple investors to fund a project. The project succeeds only if the capital raised exceeds a stochastic threshold, and the firm offers payments contingent on success. We study the firm's optimal unique-implementation scheme, namely the scheme that guarantees the firm the maximum payoff. This scheme pays investors differential net returns (per unit of capital) depending on the size of their investments. We show that if the distribution of the investment threshold is log-concave, larger investors receive higher net returns than smaller investors. Moreover, higher dispersion in investor size increases the firm's payoff. Our analysis highlights strategic risk as an important potential driver of inequality.
\end{abstract}

JEL Codes: D86, G24, L24.

Keywords: mechanism design, contracting with externalities, collective action problem, strategic complementarities, unique implementation.

${ }^{*}$ We thank Sandeep Baliga, Dan Barron, Dirk Bergemann, Aislinn Bohren, John Geanakoplos, Hugo Hopenhayn, Navin Kartik, George Mailath, Stephen Morris, Roger Myerson, Dimitris Papanikolaou, Andy Postlewaite, Mike Powell, Phil Reny, Larry Samuelson, Ilya Segal, Andy Skrzypacz, Jean Tirole, Pierre Yared, and various seminar and conference audiences for helpful comments.

$\dagger$ Yale University and CEPR. Email: marina.halac@yale.edu.

¥The Hebrew University and University of Warwick. Email: ikremer@huji.ac.il

$\S$ The Hebrew University and Lancaster University. Email: mseyal@mscc.huji.ac.il 


\section{Introduction}

Firms often have worthwhile projects that require the participation of multiple investors. A key problem is that these investors face strategic risk: if not enough of them choose to invest, the firm will not have enough capital to implement its project and generate a return. As a result, there may be outcomes in which some or all the investors choose not to invest because they expect that others will not invest. These outcomes are bad for the firm and typically inefficient.

This paper studies the firm's optimal scheme that guarantees investment as the unique outcome. In a world without contracting constraints, where payments can be made contingent on third parties' choices, eliminating the possibility of bad outcomes would impose no extra cost on the firm. But the real world is not unconstrained, and as pointed out by the literature, bilateral contracts are often all a firm can rely on. ${ }^{1}$ Guaranteeing investment then requires the firm to compensate investors for their strategic risk, a risk that depends on the amount of capital each investor pledges. A natural question arises: how does heterogeneity in investor size affect the firm's scheme and the returns yielded to the firm and the investors? In particular, does an optimal scheme treat investors differently based on size, and, if so, which investors get better terms? How does the distribution of capital among investors affect the firm's profits and the feasibility of investment?

Our model consists of a firm and a set of agents. The firm owns a project that generates a surplus if implemented, and each agent has an amount of capital to invest, which varies across the agents. The firm's project can be implemented-i.e., the project "succeeds" - only if the capital raised from the agents exceeds a stochastic, initially unknown threshold. ${ }^{2}$ The firm offers each agent two payments for investing, one if the project succeeds and another if it fails. Each agent then chooses whether to invest with the firm or put her capital in a safe asset that pays a fixed net return. We characterize the firm's optimal unique-implementation scheme. This scheme specifies individual capital amounts and the least-cost payments such that investing these amounts with the firm is the unique Nash equilibrium outcome. ${ }^{3}$

\footnotetext{
${ }^{1}$ See Section 2 as well as the discussions in Innes and Sexton (1994) and Segal (2003).

${ }^{2}$ This threshold captures common factors such as the project involving inputs whose prices are random, or the firm having a stochastic source of external credit to use as additional funding. More abstractly, our model simply assumes that the probability of project success is increasing in the amount of capital invested.

${ }^{3}$ Formally, we require that the equilibrium be unique if the payments that the firm offers under success are increased by any positive amount. See Section 2 for details. Our unique implementation requirement is equivalent to having the firm maximize its expected payoff in its worst possible equilibrium outcome.
} 
Our first main result addresses how the optimal returns that the firm offers vary with investor size, given a fixed set of investors. We show that if the project fails, the firm simply refunds the agents their capital, thus paying the same zero net return to each of them. ${ }^{4}$ However, if the project succeeds, the firm pays the agents differential net returns depending on the size of their investments. Under a distributional assumption (which we discuss subsequently), we show that agents with larger amounts of capital receive higher net returns (per unit of capital) than those with smaller amounts. This pattern is consistent with evidence from private equity, where large limited partners are given preferential terms compared to small ones (see, e.g., Clayton, 2017). By showing that larger investors get more per unit invested, this result also has implications for dynamic capital markets: we identify a mechanism through which capital becomes dispersed, pointing to "winner-takes-all dynamics" such as those that arise in tournament theory and models of superstars (Lazear and Rosen, 1981; Rosen, 1981).

Our second main result concerns the optimal set of investors for the firm. Fixing the total amount of capital, we find that the firm benefits from dealing with agents whose capital is more unequal. Specifically, any mean-preserving spread of the capital distribution (in the sense of second-order stochastic dominance) reduces the firm's cost of raising any given level of agents' capital. Higher dispersion in investor size therefore increases the firm's expected payoff from any given investment, as well as the range of investments that are feasible. Furthermore, as an implication, we find that the firm targets those agents with the largest endowments of capital, generating differences not only in agents' net investment returns but also in their access to investment opportunities.

Our last main result considers the relationship between the distribution of capital and the distribution of returns. One might be tempted to conclude from our previous results that not only larger investors are offered higher net returns, but also their return advantage is larger when the agents' investments are more unequal. We show that the opposite is true, in the following sense: higher capital dispersion reduces the difference in net returns between the largest and smallest investors. In fact, we find that this return difference can decline to the extent that even the difference in the investors' final capital holdings declines when initial capital becomes more unequal.

To provide intuition for these results, we next describe a simple example. Consider a project that requires $I$ units of capital to succeed, where the threshold $I$ is uniformly distributed on the interval $[0,30]$. If the project succeeds, it generates a fixed surplus

\footnotetext{
${ }^{4}$ This result applies to our benchmark setting with no initial firm capital. If the firm owns initial capital, a subset of the agents are paid a positive net return under failure; yet, as shown in Section 5, our qualitative conclusions are unchanged.
} 
$A>0$ in addition to the initial investment. Suppose the firm wishes to guarantee full investment by two agents, where agent 1 has 10 units of capital and agent 2 has 20 units. The agents' outside option is to invest in a safe asset that pays a net return of $10 \%$.

In this simple example, the project succeeds for sure if both agents invest with the firm. Hence, paying each agent a net return under success equal to the safe return of $10 \%$ would suffice to induce an equilibrium in which both agents invest. However, an equilibrium in which neither agent invests would also exist given this (or a slightly higher) return. To implement full investment as the unique equilibrium outcome, the firm must make it dominant for one of the agents to invest.

Consider first a scheme that makes investment dominant for agent 1. If only agent 1 invests, the project succeeds with probability $1 / 3$, namely the probability that the investment threshold is $I \leq 10$. To ensure that agent 1 invests no matter what agent 2 does, it thus suffices to offer her a net return under success (slightly above) $r$ satisfying $r / 3=10 \%$, i.e. $r=30 \%$. Given agent 1's participation, it then suffices to offer agent 2 a net return of $10 \%$ for her to also invest. It follows that the firm can guarantee full investment at a cost of $10(30 \%)+20(10 \%)=5$.

The alternative is to make investment dominant for agent 2 . If only agent 2 invests, the project succeeds provided that $I \leq 20$, which occurs with probability $2 / 3$. Thus, it suffices to offer agent 2 a net return under success of $15 \%$ to guarantee her participation. Since agent 1 will then invest as well if she is offered at least 10\%, the firm's cost is now equal to $10(10 \%)+20(15 \%)=4$, which is lower than under the previous scheme. Intuitively, agent 2's larger investment provides her with more self-insurance compared to agent 1, and this allows the firm to pay a lower compensation for risk when agent 2's participation is made dominant. Consequently, the firm uses a scheme that pays a higher net return to the large investor compared to the small investor. This illustrates our first main result.

Consider next transferring capital from the small to the large investor. For example, suppose we transfer 4 units of capital from agent 1 to agent 2, so that the capital of agent 1 becomes 6 and that of agent 2 becomes 24. Following analogous steps to those above, the firm's scheme in this case entails a net return under success of $12.5 \%$ for agent 2 and $10 \%$ for agent 1 . The firm's cost is equal to $6(10 \%)+24(12.5 \%)=3.6$, which is lower than the cost of 4 prior to the transfer. Because the large investor becomes better self-insured when her capital is increased, the overall compensation for risk that the firm has to pay declines. We thus obtain that when the distribution of capital is more unequal, the firm's expected payoff is higher, and a lower surplus $A$ from success 
suffices for the investment to be profitable. This illustrates our second main result. Our third main result is also clear in this exercise: the difference in the agents' net returns is smaller when their investments are more heterogeneous.

Our paper examines a general setting in which the number of agents and their capital levels are arbitrary, as is the distribution of the investment threshold $I$. We identify a condition on the distribution function of $I$ under which our results hold for all capital distributions. The condition is that the inverse of the distribution function be convex, a property that is implied by log-concavity of the distribution and thus satisfied by most commonly used distribution functions. ${ }^{5}$ Our analysis elucidates the role of this condition and how our findings change if it is not satisfied. In the example above, the condition implies a risk premium per unit of capital which is decreasing and convex in the agents' investments, and this is why the firm minimizes costs by first guaranteeing the participation of the large investor.

We show that our results extend to a setting in which the firm has some initial capital of its own. The firm in this case uses its initial capital to fully insure small investors, thus continuing to offer higher net returns to larger investors. Our results are also robust to alternative specifications of the project returns. Moreover, while derived for a firm that maximizes its profits, our findings are also relevant to a social planner concerned with agents' welfare.

Beyond capital-raising, we discuss how our model may be applied to other contracting problems with externalities. These include a monopolist offering exclusive dealing contracts to buyers to deter market entry; a firm rewarding workers to complete a joint task; and a bank offering interest and collateral to depositors to prevent a run. Heterogeneity is common in these situations, and our results can be useful to understand its implications.

A broad insight from our analysis is that strategic risk may be a driver of inequality. A profit-maximizing mechanism favors certain agents in order to pin down their choices and reduce the strategic risk on the part of other agents. We show that under a plausible condition, the more favorable terms are given to those agents who are already in a more favorable position. The mechanism therefore exacerbates initial differences among the agents, and it also benefits from these differences. Inequality being undesirable for a number of reasons that we do not study, our paper uncovers important economic forces that may be behind it. We discuss policy implications for a social planner in Section 6 .

\footnotetext{
${ }^{5}$ These include the exponential, gamma, log-normal, Pareto, and uniform distributions (see Bagnoli and Bergstrom, 2005).
} 
Related literature. Our model is one of multi-agent contracting, related to the work by Segal (1999, 2003) and Bernstein and Winter (2012), among others. These are abstract models with externalities among the agents which are exogenously given. In contrast, we consider an applied problem in which the externalities among the agents are endogenously determined by the firm's contract offers, and in which contracts are required to satisfy the firm's budget constraint.

Our main departure from the literature is that we study agents who are heterogeneous in their endowments. As such, we obtain a number of results that have no parallel in other models. It is worth noting that while heterogeneity is our focus, our analysis also has implications for the case in which agents are homogeneous. Specifically, we find that the firm's optimal scheme gives differential net returns to the agents even if they all have the same amount of capital. This is analogous to the results in Winter (2004), where an optimal team incentive scheme is shown to discriminate among ex ante identical workers. Similar results appear in Segal (2003) and Eliaz and Spiegler (2015), as well as in Inostroza and Pavan (2018) in the context of persuasion. Given that an optimal scheme creates heterogeneity among homogenous agents, our paper studies the natural question of how the scheme deals with heterogeneous agents.

Two related papers that analyze heterogeneity are Bernstein and Winter (2012) and Sákovics and Steiner (2012). Unlike our model, neither of these feature contingent payments: the principal offers fixed subsidies for the agents to participate in the mechanism, and agents' benefits from participating and their externalities are exogenous. Bernstein and Winter (2012) study how asymmetries in the agents' bilateral externalities affect the principal's scheme and revenue. Instead, we look directly at differences in agents' attributes, whose effects on the matrix of externalities may be complex and endogenous. In fact, while in our model the magnitude of an investor's externality is related to size, we find that the relationship between size and contract terms depends on a distributional condition, so a higher externality does not necessarily imply more favorable terms as in Bernstein and Winter. The difference arises primarily from the fact that here agents' externalities are neither bilateral nor additive. In our framework, the externality that an agent exerts on another agent's gains depends on who else is in the pool of investors.

Sákovics and Steiner (2012) consider a global game with incomplete information, where agents differ in their influence over the aggregate action, benefit from project success, and cost of investment. They obtain a coarse monotonicity result whereby agents receive full, partial, or no subsidy depending on their influence-to-benefit ratio. There is no analog in their paper to our finding that an optimal scheme increases agents' initial 
differences, nor to the condition that we identify for this result to hold. Our analysis of how payoffs change when agents become more heterogeneous is another departure from their work.

Finally, there is a literature on capital-raising for new projects. Particularly relevant is Akerlof and Holden (2018), which shares our motivation of examining the role of investor size. ${ }^{6}$ The paper differs in various aspects, most importantly in that it is not concerned with optimal mechanism design. The authors compare equilibrium outcomes under different market configurations, using risk dominance to select among multiple equilibria. They show that the presence of a large investor who moves first can change the risk-dominant equilibrium from a low-investment to a high-investment one. In a competitive market setting with many projects, the large investor can thus earn rents.

\section{Model}

\section{$2.1 \quad$ Setup}

A firm owns a project which yields a fixed surplus $A>0$ if implemented. The firm can implement the project only if the capital invested in it exceeds an initially unknown, stochastic threshold $I$. We assume that $I$ has a twice differentiable distribution function $F$ with support $[0, \bar{I}]$, for some $\bar{I}>0 .{ }^{7}$ Hence, if capital $x$ is invested, with probability $F(x)$ the threshold satisfies $I \leq x$ and the project is implemented, yielding final capital $x+A .^{8}$ With the remaining probability $1-F(x)$ the threshold is $I>x$ and the project is not implemented, so the final capital is $x$. We will refer to project implementation as success and to no implementation as failure.

We begin by assuming that the firm has no capital of its own, deferring the study of how the firm would use any initial capital to Section 5. The firm raises capital from a set of $N>1$ heterogeneous agents, indexed by $n \in S=\{1, \ldots, N\}$. Each agent $n$ has a capital endowment $\bar{x}_{n}>0$. Instead of investing with the firm, agents can invest their capital in a safe asset that pays a net return $\theta>0$. (All returns are net percentage returns, meaning that if agent $n$ invests $\bar{x}_{n}$ in the safe asset, her payoff is $(1+\theta) \bar{x}_{n}$.) All of this is common knowledge.

\footnotetext{
${ }^{6}$ See also Andreoni (1998) and Akerlof and Holden (2016).

${ }^{7}$ Setting the lower bound of the support to zero simplifies the exposition. As will be clear in the next sections, our results are unchanged so long as this bound is smaller than the largest investor's amount of capital, and our problem is moot otherwise.

${ }^{8}$ In Section 6, we show that our results also apply if the firm's surplus from implementing the project is proportional to the capital invested instead of a constant amount.
} 
The order of moves is as follows. First, the firm offers each agent a contract specifying payments in the events of project success and failure, as we describe in the next subsection. Second, the agents decide simultaneously whether to invest with the firm or put their capital in the safe asset. Finally, the investment threshold $I$ is realized, the project is implemented if and only if the capital raised by the firm exceeds $I$, and payments are made.

\subsection{Firm's problem}

The firm wishes to guarantee its maximum possible payoff. Its problem is to choose a payoff-maximizing scheme subject to satisfying its budget constraint and to inducing a unique equilibrium outcome.

As further discussed in Section 2.3, we focus on contracts that are bilateral and simple. For each $n \in S$, the firm specifies an amount of capital $x_{n} \in\left[0, \bar{x}_{n}\right]$ and returns $\left(r_{n}, k_{n}\right)$ conditional on agent $n$ investing $x_{n}$ in the firm's project. The return $r_{n}$ is the net return that agent $n$ receives if the project succeeds; the return $k_{n}$ is the agent's net return in the case of failure.

Given a scheme specifying investments $\left(x_{n}\right)_{n \in S}$ and returns $\left(r_{n}, k_{n}\right)_{n \in S}$, denote agent $n$ 's decision by $y_{n} \in\{0,1\}$, where $y_{n}=1$ means invest $x_{n}$ with the firm and $y_{n}=0$ means invest $x_{n}$ in the safe asset. The firm's budget constraint requires that the total payments offered to the agents do not exceed the firm's final capital, regardless of the set of agents who invest in the project and whether or not the project is implemented. That is, for all profiles of choices $\mathcal{Y}=\left(y_{1}, \ldots, y_{N}\right)$, the firm's scheme must satisfy

$$
\sum_{n=1}^{N} r_{n} y_{n} x_{n} \leq A \quad \text { and } \quad \sum_{n=1}^{N} k_{n} y_{n} x_{n} \leq 0
$$

In addition, the firm's scheme must implement the agents' investments in a unique outcome. The firm's problem can be decomposed in two steps:

(i) For fixed capital amounts $\left(x_{n}\right)_{n \in S}$, find the optimal scheme $\left(r_{n}, k_{n}\right)_{n \in S}$ guaranteeing investments $\left(x_{n}\right)_{n \in S}$.

(ii) Given step (i), find the optimal capital amounts $\left(x_{n}\right)_{n \in S}$, where $x_{n} \in\left[0, \bar{x}_{n}\right]$ for each $n \in S$.

We will address step (i) in Section 3 and step (ii) in Section 4. We next formalize the firm's problem in step (i). 
Fix capital amounts $\left(x_{n}\right)_{n \in S}$ where, to avoid trivialities and without loss, we take $x_{n}>0$ for each $n \in S$. Given $\left(x_{n}\right)_{n \in S}$, say that a scheme $\left(r_{n}, k_{n}\right)_{n \in S}$ is incentive inducing (INI) if $\mathcal{Y}^{1} \equiv(1, \ldots, 1)$ is the unique Nash equilibrium of the game induced by $\left(r_{n}, k_{n}\right)_{n \in S}$. Since the set of INI schemes is open (because $r_{n}$ and $k_{n}$ take continuous values), we define an optimal scheme as the least-cost scheme $\left(r_{n}, k_{n}\right)_{n \in S}$ such that, for any $\varepsilon>0$, raising $r_{n}$ by $\varepsilon$ for each $n \in S$ yields an INI scheme. ${ }^{9}$ Formally, let $U_{n}\left(y_{n}, \mathcal{Y}_{-n}\right)$ be agent $n$ 's expected return on $x_{n}$ given net returns $\left(r_{n}, k_{n}\right)$, investment choice $y_{n}$, and investment choices $\mathcal{Y}_{-n}=\left(y_{1}, \ldots, y_{n-1}, y_{n+1}, \ldots, y_{N}\right)$ of the other agents:

$$
U_{n}\left(y_{n}, \mathcal{Y}_{-n}\right)=\left[F\left(\sum_{n^{\prime}=1}^{N} y_{n^{\prime}} x_{n^{\prime}}\right) r_{n}+\left(1-F\left(\sum_{n^{\prime}=1}^{N} y_{n^{\prime}} x_{n^{\prime}}\right)\right) k_{n}\right] y_{n} x_{n}+\theta\left(1-y_{n}\right) x_{n}
$$

A profile $\mathcal{Y}^{\prime}=\left(y_{1}^{\prime}, \ldots, y_{N}^{\prime}\right)$ is a Nash equilibrium if and only if $y_{n}^{\prime} \in \operatorname{argmax}_{y \in\{0,1\}} U_{n}\left(y, \mathcal{Y}_{-n}^{\prime}\right)$ for all $n \in S$. Let $E\left(\left(r_{n}, k_{n}\right)_{n \in S}\right)$ be the set of Nash equilibrium profiles under scheme $\left(r_{n}, k_{n}\right)_{n \in S}$. An optimal scheme $\left(r_{n}, k_{n}\right)_{n \in S}$ must satisfy the following two conditions:

$$
\mathcal{Y}^{1} \in E\left(\left(r_{n}, k_{n}\right)_{n \in S}\right)
$$

If $\mathcal{Y} \in E\left(\left(r_{n}, k_{n}\right)_{n \in S}\right), \mathcal{Y} \neq \mathcal{Y}^{1}$, then $U_{n}\left(1, \mathcal{Y}_{-n}\right)=U_{n}\left(0, \mathcal{Y}_{-n}\right), y_{n}=0$ for some $n$

(C1) says that there exists a Nash equilibrium in which each agent $n \in S$ invests $x_{n}$ with the firm. (C2) says that in any Nash equilibrium in which some agents $n \in S$ do not invest $x_{n}$ with the firm, at least one such non-investing agent is willing to invest $x_{n}$ with the firm. These conditions are necessary and sufficient for the scheme $\left(r_{n}+\varepsilon, k_{n}\right)_{n \in S}$ to be an INI scheme for any $\varepsilon>0 .^{10}$

Let $X_{N} \equiv \sum_{n=1}^{N} x_{n}$. An optimal scheme $\left(r_{n}^{*}, k_{n}^{*}\right)_{n \in S}$ guaranteeing investments $\left(x_{n}\right)_{n \in S}$ solves the following program:

$$
\max _{\left(r_{n}, k_{n}\right)_{n \in S}} V=\left(A-\sum_{n=1}^{N} r_{n} x_{n}\right) F\left(X_{N}\right)-\sum_{n=1}^{N} k_{n} x_{n}\left(1-F\left(X_{N}\right)\right)
$$

subject to $(\mathrm{BC}),(\mathrm{C} 1)$, and $(\mathrm{C} 2)$.

\footnotetext{
${ }^{9}$ Note that an optimal scheme is not itself INI as it admits equilibria which are not full participation. However, paying each agent slightly more under success eliminates all such equilibria. This definition is equivalent to assuming that agents invest with the firm when indifferent given their conjectures.

${ }^{10}$ Necessity is immediate. Sufficiency follows from Lemma 1 in the next section.
} 


\subsection{Discussion of assumptions}

Before we solve the firm's problem, it is worth discussing some of our model assumptions.

First, we have assumed that the firm cannot coordinate the agents to its preferred equilibrium when multiple equilibria exist. This assumption is what motivates the requirement of unique implementation, both in our paper and in related work (Segal, 2003; Winter, 2004; Bernstein and Winter, 2012). If there are multiple equilibria, agents may play a non-desirable one; indeed, several experiments find that subjects are often trapped in bad equilibrium outcomes in environments with externalities (see, e.g., Devetag and Ortmann, 2007). Our unique implementation requirement is equivalent to having the firm maximize its profits in the equilibrium outcome yielding the lowest profits for the firm. ${ }^{11}$ Naturally, if the firm could instead "pick" the equilibrium to be played by the agents, then it would be able to extract the full surplus by specifying returns $\left(r_{n}, k_{n}\right)=\left(\theta / F\left(X_{N}\right), 0\right)$ for each $n \in S$ and some $\left(x_{n}\right)_{n \in S}$. Under such a scheme, there is an equilibrium that implements investments $\left(x_{n}\right)_{n \in S}$ and keeps all agents to their outside option, but equilibria with lower investment also exist.

Second, we have posited that the agents make their investment choices simultaneously, i.e. under imperfect information. Our analysis is unchanged if instead the agents move sequentially, with each agent observing the decisions of her predecessors, so long as we continue to consider all Nash equilibria of the game. If subgame perfection is imposed, the problem becomes trivial: by offering $r_{n}=\theta / F\left(X_{N}\right)$ (plus $\varepsilon>0$ arbitrarily small) and $k_{n}=0$ to each agent $n \in S$, the firm induces investments $\left(x_{n}\right)_{n \in S}$ as the unique subgame-perfect Nash equilibrium of the sequential game, thus extracting the full surplus. ${ }^{12}$ We view the simultaneous game as a simple (and stark) way to capture the fact that investors in reality have limited information about others' investment choices, and their decisions are not sequential insofar as they can be revised.

Third, following the literature (Segal, 2003; Winter, 2004), we have assumed that the firm can rely on bilateral contracts only. That is, contracts cannot directly condition on third parties' actions: the payment to an agent does not depend on other agents' investment decisions except insofar as these decisions affect whether the project gets implemented. The motivation for this restriction stems from the difficulty to verify in practice the capital pledged by third parties. If an agent sues for breach of contract, a court can require the agent to prove that she invested with the firm (or else she lacks

\footnotetext{
${ }^{11}$ See Segal (2003) for a general argument.

${ }^{12}$ If we impose subgame perfection but require that investment with the firm be a dominant strategy in each subgame (as in Innes and Sexton, 1994, for example), then our results apply.
} 
standing to sue), and it can plausibly verify whether or not the firm implemented some large project. It is less clear whether the court can identify the firm's other investors and the amounts that they invested. We focus on situations in which it cannot. If instead contracts can condition on third parties' choices, then again the firm would be able to extract the full surplus.

Fourth, we have also restricted attention to contracts that are "simple." Specifically, our analysis abstracts from menu contracts in which the firm offers an agent $n$ different returns $\left(r_{n}\left(x_{n}^{\prime}\right), k_{n}\left(x_{n}^{\prime}\right)\right)$ for different amounts $x_{n}^{\prime}$ that the agent may choose to invest. In a simple contract, the firm specifies an amount $x_{n}$ and returns $\left(r_{n}, k_{n}\right)$ conditional on the agent investing that amount (and zero returns otherwise). Naturally, only simple contracts are relevant if agents' decisions are binary, as is the case when there are indivisibilities in investment. ${ }^{13}$ Moreover, even when investment is fully divisible, we provide conditions in the Online Appendix under which simple contracts are without loss of optimality. ${ }^{14}$

Finally, we have required that the firm satisfy its budget constraint both on and off the equilibrium path. That is, the firm must be able to follow through on its commitments to the agents regardless of which agents decide to invest in the project. ${ }^{15}$ An alternative possibility would be to allow the firm to offer any scheme $\left(r_{n}, k_{n}\right)_{n \in S}$ that satisfies its budget constraint on the equilibrium path (i.e. under the investments $\left(x_{n}\right)_{n \in S}$ ), and each agent $n \in S$ would then assess the credibility of her offer $\left(r_{n}, k_{n}\right)$ according to her conjecture of others' behavior. We show in the Online Appendix that, given our focus on unique implementation, both possibilities yield the same results. We regard the stronger budget-balance condition as more plausible, since the irrational behavior of some investors cannot serve the firm with an excuse for not fulfilling its contracts with other investors.

\section{Optimal Scheme}

In this section, we address step (i) of the firm's problem: for fixed capital amounts $\left(x_{n}\right)_{n \in S}$, we study the firm's optimal scheme that guarantees these investments, namely the scheme that solves program (P). Without loss, we take $x_{n}>0$ for each $n \in S$. We begin by restating constraints $(\mathrm{C} 1)-(\mathrm{C} 2)$ in program $(\mathrm{P})$ using the following equivalence:

\footnotetext{
${ }^{13}$ Indivisibilities are common in applications where capital takes the form of a specific resource or skill, or where the project requires a number of discrete investments. See Section 6 for some examples.

${ }^{14}$ See Segal (2003) for an analysis of menu contracts in a more general setting.

${ }^{15}$ This is analogous, for example, to the requirements in Holmström (1982).
} 
Lemma 1. (C1)-(C2) hold if and only if there exists a permutation $\pi=\left(n_{1}, \ldots, n_{N}\right)$ of the set of agents such that, for each $i \in S$, agent $n_{i}$ is willing to invest with the firm if agents $\left(n_{1}, \ldots, n_{i-1}\right)$ invest with the firm, no matter what the other agents do.

An optimal scheme makes it iteratively dominant for each agent to invest with the firm. To see why this follows from $(\mathrm{C} 1)-(\mathrm{C} 2)$, note that by $(\mathrm{C} 2)$, there must exist an agent $n_{1}$ who is willing to invest with the firm when no other agent does. Moreover, by (C1), this agent must also be willing to invest when all other agents do. We show that as a result, $n_{1}$ is willing to invest with the firm no matter what the other agents do. The reason is that $n_{1}$ 's expected payoff from investing is a weighted average of her returns under success and under failure, where the weights are the probabilities of each event and thus achieve their highest and lowest values when all and none of the other agents invest. Having established this property for $n_{1}$, we then use an induction argument to complete the proof of the "only if" claim in Lemma $1 .{ }^{16}$

Given this result, it will be useful (and without loss) to study schemes which specify some permutation $\pi=\left(n_{1}, \ldots, n_{N}\right)$ of the set of agents and returns $\left(r_{i}, k_{i}\right)$ for each agent $n_{i} \in S$. We proceed by first characterizing the optimal returns $\left(r_{i}^{*}, k_{i}^{*}\right)_{i \in S}$ and then solving for an optimal permutation $\pi^{*}=\left(n_{1}^{*}, \ldots, n_{N}^{*}\right)$.

\section{$3.1 \quad$ Optimal returns}

Given a permutation $\pi=\left(n_{1}, \ldots, n_{N}\right)$, denote the aggregate capital of the first $i$ agents in the permutation by $X_{i} \equiv \sum_{j=1}^{i} x_{n_{j}}$, where we omit the dependence on $\pi$ to ease the exposition. (Note that, as previously defined, $X_{N}$ corresponds to the total amount of capital.) We obtain:

Proposition 1. Suppose that there exists an optimal scheme guaranteeing investments $\left(x_{n}\right)_{n \in S}$. Any such scheme specifies some permutation $\pi=\left(n_{1}, \ldots, n_{N}\right)$ and returns $\left(r_{i}^{*}, k_{i}^{*}\right)_{i \in S}$ such that, for each $i \in S$, agent $n_{i}$ is indifferent over investing with the firm if agents $\left(n_{1}, \ldots, n_{i-1}\right)$ invest with the firm and agents $\left(n_{i+1}, \ldots, n_{N}\right)$ do not. Moreover, the following returns are optimal:

$$
r_{i}^{*}=\frac{\theta}{F\left(X_{i}\right)} \text { and } k_{i}^{*}=0
$$

An optimal scheme implies a permutation $\pi=\left(n_{1}, \ldots, n_{N}\right)$ such that the first agent

\footnotetext{
${ }^{16}$ The proof of Lemma 1 is general in that it does not rely on specific externalities between the agents. The result will also apply to the setting studied in Section 5 in which the firm owns some initial capital.
} 
in the permutation is indifferent between investing and not when no other agent invests, the second agent is indifferent between investing and not when the first agent invests and the others do not, and so on. For intuition, recall that by Lemma 1, there is a permutation $\pi=\left(n_{1}, \ldots, n_{N}\right)$ in which each agent $n_{i}$ is willing to invest when agents $\left(n_{1}, \ldots, n_{i-1}\right)$ invest, no matter the rest. This implies that for each $i \in S$ and each $j \in\{i, \ldots, N\}$,

$$
r_{i}^{*} F\left(X_{j}\right)+k_{i}^{*}\left(1-F\left(X_{j}\right)\right) \geq \theta .
$$

Now note that the firm's budget constraint (BC) requires $k_{i} \leq 0$ for each $i \in S$; given no initial capital of its own, the firm cannot credibly commit to pay an agent a positive return under failure. Since the agents can obtain a net return $\theta>0$ by investing in the safe asset, condition (1) then requires that the firm offer a strictly positive net return $r_{i}>0$ under success. It follows that for each $i \in S$,

$$
r_{i}^{*}>0 \geq k_{i}^{*}
$$

and thus the scheme induces strategic complementarities. That is, under an optimal scheme, each agent $n_{i}$ 's expected payoff from investing with the firm is increasing in the other agents' investments.

The strategic complementarities in turn simplify the agents' participation constraints. Given the inequalities in (2), we obtain that condition (1) is satisfied for each $i \in S$ and each $j \in\{i, \ldots, N\}$ if and only if it is satisfied for each $i \in S$ and $j=i$ : the firm can induce agent $n_{i}$ to participate no matter what agents $\left(n_{i+1}, \ldots, n_{N}\right)$ do if it can induce agent $n_{i}$ to participate when all such other agents do not. Furthermore, we show that by optimality, condition (1) must hold with equality for each $i \in S$ and $j=i$ : otherwise, the firm could lower a return $r_{i}$ and increase its payoff while preserving incentives and relaxing its budget constraint. Therefore, we obtain

$$
r_{i}^{*} F\left(X_{i}\right)+k_{i}^{*}\left(1-F\left(X_{i}\right)\right)=\theta
$$

for each $i \in S$. This yields the first part of Proposition 1, which, in the literature's jargon, shows that any optimal scheme is a "divide and conquer" scheme. ${ }^{17}$

The second part of Proposition 1 uses the binding participation constraints in (3) to derive optimal returns. We show that it is optimal to set $\left(r_{i}^{*}, k_{i}^{*}\right)=\left(\theta / F\left(X_{i}\right), 0\right)$

\footnotetext{
${ }^{17}$ See Segal (2003). Divide and conquer strategies are also discussed in the literature on exclusionary contracts, including Rasmusen, Ramseyer and Wiley (1991), Innes and Sexton (1994), and Segal and Whinston (2000).
} 
for each $i \in S$. The idea is intuitive. The firm conditions on all agents $\left(n_{1}, \ldots, n_{N}\right)$ investing in the project, whereas, as shown in (3), each agent $n_{i}$ conditions on only agents $\left(n_{1}, \ldots, n_{i}\right)$ investing. Hence, the firm assigns a higher probability to success than each agent $n_{i}$ does, which means that the firm values $r_{i}$ relative to $k_{i}$ more than each agent $n_{i}$. As a consequence, the firm benefits from reducing $r_{i}$, and thus increasing $k_{i}$, as much as it can, subject to its budget constraint (BC) and the participation constraints in (3).

Formally, we show that if a scheme specifies $k_{i}<0$ for some $i \in S,{ }^{18}$ we can perform a perturbation in which we increase $k_{i}$ by $\varepsilon>0$ arbitrarily small and reduce $r_{i}$ so as to keep the left-hand side of (3) unchanged. The perturbed scheme satisfies the firm's budget constraint and preserves the agents' incentives. Moreover, we show that the perturbation increases the firm's expected payoff in $(\mathrm{P})$. It follows that it is optimal to set $k_{i}^{*}=0$ and thus, by $(3), r_{i}^{*}=\theta / F\left(X_{i}\right)$ for each $i \in S .{ }^{19}$

Proposition 1 has important implications for the agents' payoffs. The proposition shows that the firm treats the agents symmetrically under failure: each agent is refunded her capital if the project is not implemented. However, in the case of success, returns differ across the agents. Given the permutation $\pi=\left(n_{1}, \ldots, n_{N}\right)$, agents who are positioned towards the beginning of the permutation are offered a higher net return (per unit of capital invested) than those positioned later in the permutation. The reason is that agents with a higher rank $i$ condition on a larger set of other agents investing with the firm; thus, given the strategic complementarities, their participation constraints are less costly to satisfy. Clearly, in light of this result, a key question is how an optimal permutation $\pi^{*}$ ranks the agents given the heterogeneity in their capital amounts. We turn to this question in the next subsection.

A useful property of the returns in Proposition 1 is that they maximally relax the firm's budget constraint. Specifically, since $k_{i}^{*}=0$ for each $i \in S$, these returns minimize not only the firm's total costs but also its costs under success, $\sum_{i=1}^{N} r_{i} x_{n_{i}}$, for some permutation $\pi$. It follows that an optimal scheme guaranteeing investments $\left(x_{n}\right)_{n \in S}$ exists if and only if a scheme with returns $\left(r_{i}^{*}, k_{i}^{*}\right)=\left(\theta / F\left(X_{i}\right), 0\right)$ for some permutation $\pi$ satisfies (BC). As formalized in the next corollary, the latter requires that the firm's surplus $A$ from success be large enough.

\footnotetext{
${ }^{18}$ Recall that the firm's budget constraint requires $k_{i} \leq 0$ for each $i \in S$.

${ }^{19}$ These returns are strictly optimal for $i \in\{1, \ldots, N-1\}$ and weakly optimal for $i=N$.
} 
Corollary 1. An optimal scheme guaranteeing investments $\left(x_{n}\right)_{n \in S}$ exists if and only if there exists a permutation $\pi=\left(n_{1}, \ldots, n_{N}\right)$ such that

$$
\sum_{i=1}^{N} \frac{\theta}{F\left(X_{i}\right)} x_{n_{i}} \leq A .
$$

We end our discussion of Proposition 1 with a remark. As noted above, the firm's scheme induces a supermodular game among the agents, namely one characterized by strategic complementarities. As a result, our requirement of unique implementation in Nash equilibria also yields unique implementation in rationalizable strategies.

Remark 1. Take an optimal scheme guaranteeing investments $\left(x_{n}\right)_{n \in S}$. Then $\left(x_{n}\right)_{n \in S}$ is a Nash equilibrium and no other outcome is rationalizable.

\subsection{Optimal permutation}

We now turn to the question of how an optimal permutation ranks the agents. Assume hereafter that the condition in Corollary 1 holds, so an optimal scheme guaranteeing investments $\left(x_{n}\right)_{n \in S}$ exists. By Proposition 1, it is optimal for the firm to specify some permutation $\pi=\left(n_{1}, \ldots, n_{N}\right)$ of the set of agents and returns $\left(r_{i}^{*}, k_{i}^{*}\right)=\left(\theta / F\left(X_{i}\right), 0\right)$

for each agent $n_{i} \in S$. Substituting in the firm's expected payoff in $(\mathrm{P})$, under such a scheme the firm obtains

$$
V=\left(A-\theta \sum_{i=1}^{N} \frac{x_{n_{i}}}{F\left(X_{i}\right)}\right) F\left(X_{N}\right) .
$$

It follows from (4) and Corollary 1 that a permutation $\pi=\left(n_{1}, \ldots, n_{N}\right)$ is optimal if and only if it minimizes the firm's costs under success, given by

$$
\theta \sum_{i=1}^{N} \frac{x_{n_{i}}}{F\left(X_{i}\right)} .
$$

The next proposition shows that (5) is minimized by ranking the agents in decreasing order of the size of their investments, provided that a condition on the investment threshold distribution holds. This condition is that $1 / F(x)$ be convex (over the relevant range), and it is satisfied by most commonly used distributions, as we explain subsequently. 
Proposition 2. Suppose $1 / F(x)$ is convex for $x \in[0, X], X>0$. Then for any investments $\left(x_{n}\right)_{n \in S}$ with $X_{N} \leq X$, an optimal permutation is $\pi^{*}=\left(n_{1}^{*}, \ldots, n_{N}^{*}\right)$ such that

$$
x_{n_{1}^{*}} \geq \ldots \geq x_{n_{N}^{*}} .
$$

Consequently, larger investors receive higher net returns than smaller investors.

The logic for the optimal permutation is as follows. Given a permutation $\pi=$ $\left(n_{1}, \ldots, n_{N}\right)$, Proposition 1 shows that an optimal scheme compensates each agent $n_{i} \in S$ on the marginal unit of capital invested in the project. That is, for each unit invested by agent $n_{i}$, the firm pays the agent a return under success $r_{i}^{*}=\theta / F\left(X_{i}\right)$. If $1 / F(x)$ is convex, then the return curve $\theta / F\left(X_{i}\right)$ is decreasing and convex in the capital $X_{i}$ invested up to agent $n_{i}$. This means that the firm benefits from moving down this return curve as quickly as possible; the faster capital is accumulated along the sequence $\left(x_{n_{1}}, \ldots, x_{n_{N}}\right)$, the lower is the sum of returns that the firm has to pay under success. It follows that it is optimal to rank the agents in decreasing size order, from the agent with the largest amount of capital to that with the smallest amount.

Intuitively, to guarantee investment, the firm has to compensate the agents for the strategic risk that they face in addition to the fundamental risk. The risk premium for agent $n_{i}$ is proportional to $1 / F\left(X_{i}\right)$, which depends on the agent's rank $i$ and her amount of capital $x_{n_{i}}$. Agents with more capital face less risk because their large investment secures itself. This self-insurance reduces the risk premium that the firm has to pay to large investors, and the magnitude of the reduction depends on how sharply the risk premium drops as a function of investment. Proposition 2 thus says that large investors should be placed in the permutation according to when the risk premium drops most sharply with investment. If $1 / F\left(X_{i}\right)$ is convex, this occurs when the existing investment is small, so the firm places large investors early in the permutation. ${ }^{20}$

Figure 1 illustrates the result using the example described in the Introduction. We take $F$ uniform over $[0,30]$ and $\theta=10 \%$. The figure depicts the return curve $\theta / F\left(X_{i}\right)$, showing that the return that the firm pays under success decreases at a decreasing rate with each additional unit of capital invested in the project. If there are $N=2$ agents with capital $x_{1}=10$ and $x_{2}=20$, then by Proposition 2 the optimal permutation is $\pi^{*}=(2,1)$. That is, the firm sets $n_{1}^{*}=2$ and $n_{2}^{*}=1$ as agent 2 's capital amount is larger than agent 1's. The optimal returns under success are $r_{1}^{*}=15 \%$ for agent $n_{1}^{*}=2$ and

\footnotetext{
${ }^{20}$ Conversely, if $1 / F\left(X_{i}\right)$ is concave, the firm would benefit from placing large investors late in the permutation. See Section 6 .
} 


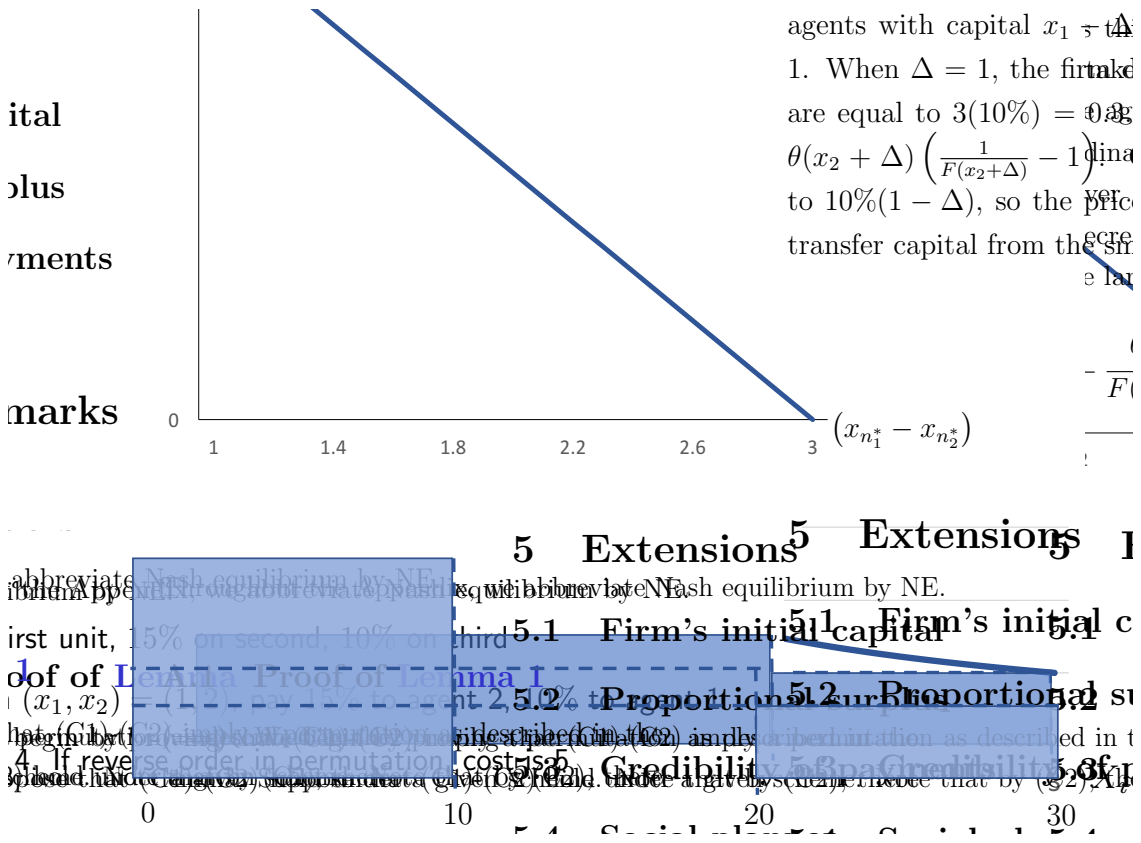

Figure 1: Return curve for $F$ uniform over [0,30] and $\theta=10 \%$. Given $N=2$ agents with capital amounts $x_{1}=10$ and $x_{2}=20$, an optimal scheme specifies the permutation $\pi^{*}=(2,1)$ and pays returns under success of $15 \%$ and $10 \%$ to agents 2 and 1 respectively.

$r_{2}^{*}=10 \%$ for agent $n_{2}^{*}=1$ (and the optimal returns under failure are equal to zero for both agents), yielding a cost for the firm of $20(15 \%)+10(10 \%)=4$. If the firm instead ranks the agents according to $\pi=(1,2)$, then the returns are $r_{1}=30 \%$ for agent $n_{1}=1$ and $r_{2}=10 \%$ for agent $n_{2}=2$, yielding a higher cost of $10(30 \%)+20(10 \%)=5$.

As stated in Proposition 2, this characterization of an optimal permutation has direct implications on investors' returns: given Proposition 1, it implies that larger investors receive higher net returns than smaller ones. The analysis therefore provides an explanation for the patterns of returns often observed in practice. As mentioned in the Introduction, our results are consistent with evidence from private equity. Tan (2016) and Clayton (2017), for example, point out an increasing tendency of private equity firms to give preferential treatment to limited partners based on size. The empirical findings in Dyck and Pomorski (2016) reveal that large investors receive higher net returns than small investors even when restricting attention to private equity investments without any preferential access. Proposition 2 suggests that these differential returns may arise as a firm's profit-maximizing solution to a coordination problem in investment.

By showing that larger investors get more per unit invested, the analysis also highlights a mechanism through which capital becomes dispersed. We find that the firm's optimal scheme exacerbates agents' initial differences. In fact, the results point to "winner- 
takes-all dynamics," whereby large investors become larger over time, even when differences in initial capital amounts may be small. These effects resemble those that arise, albeit for different reasons, in tournament theory and models of superstars (Lazear and Rosen, 1981; Rosen, 1981). ${ }^{21}$

The result in Proposition 2 holds under a condition on the distribution $F$ of the investment threshold. It is worth noting that this condition is implied by log-concavity:

Remark 2. If $F(x)$ is log-concave, then $1 / F(x)$ is convex.

Many familiar distributions are log-concave, including exponential, gamma, lognormal, Pareto, and uniform (see Bagnoli and Bergstrom, 2005). ${ }^{22}$

Finally, one may wonder about the necessity of our condition on $F$. We can show that if $1 / F(x)$ is strictly concave for some $x \in[0, X], X>0$, then there exist capital amounts $\left(x_{n}\right)_{n \in S}$ with $X_{N} \leq X$ such that a permutation that ranks the agents in decreasing size order is not optimal. Hence,

Remark 3. Convexity of $1 / F(x)$ over the relevant range is not only sufficient but also necessary for the statement in Proposition 2 to hold.

Our emphasis is on the case in which $1 / F(x)$ is convex because, as noted, most of the distributions that are frequently used satisfy this property. Moreover, $1 / F(x)$ cannot be globally concave ( since $1 / F(x) \rightarrow \infty$ as $x \rightarrow 0$ ), and thus an analysis under $1 / F(x)$ concave must be conditioned on the range of capital $\left[\min \left\{x_{n} \mid n \in S\right\}, X_{N}\right]$ given $\left(x_{n}\right)_{n \in S}$. We discuss this possibility in Section 6.

\section{Distribution of Capital}

So far we have focused on step (i) of the firm's problem, taking the amounts of capital $\left(x_{n}\right)_{n \in S}$ that the firm raises as given. We now consider step (ii): given that an optimal scheme guaranteeing investments $\left(x_{n}\right)_{n \in S}$ is characterized by Proposition 1 and Proposition 2, we study the optimal investments that the firm induces. Put differently, we ask: how does the distribution of capital among the agents impact the firm's payoff?

We compare distributions of capital using the following definition of mean-preserving spread:

\footnotetext{
${ }^{21}$ In a dynamic setting, further considerations may come into play, as the firm could potentially offer returns as a function of an agent's history of investments. See Rey and Tirole (2007) for an insightful related study in the context of cooperatives. A dynamic analysis is beyond the scope of this paper.

${ }^{22} \mathrm{Log}$-concavity of the distribution function is implied by, but weaker than, log-concavity of the density function.
} 
Definition 1. Let $H$ and $\widehat{H}$ be right-continuous, nondecreasing functions from $[0, X]$ to $\{0, \ldots, N\}$, for some $X>0$. The function $\widehat{H}$ is a mean-preserving spread of $H$ if it is second-order stochastically dominated by $H$ : for all $z \in[0, X], \int_{0}^{z} \widehat{H}(x) d x \geq$ $\int_{0}^{z} H(x) d x$, with equality for $z=X$.

For any capital amounts $\left(x_{n}\right)_{n \in S}$ and level $x>0$, let $H(x)$ denote the number of agents $n \in S$ whose capital $x_{n}$ does not exceed $x$. Clearly, the function $H$ is a rightcontinuous, nondecreasing function from $\mathbb{R}_{+}$to $\{0, \ldots, N\} .{ }^{23}$ As for the other direction, let $H$ be any right-continuous, nondecreasing function from $[0, X]$ to $\{0, \ldots, N\}$, for any $X>0$. Then the capital amounts induced by $H$ are the amounts $\left(x_{n}\right)_{n \in S}$ distributed according to $H$ : for each $n \in S, x_{n}=\min \{x \in[0, X] \mid H(x) \geq n\}$.

\subsection{Optimal investments}

The next proposition shows that for any given total investment $X_{N}$, the firm benefits from the individual investments $\left(x_{n}\right)_{n \in S}$ being more unequally distributed:

Proposition 3. Suppose $1 / F(x)$ is convex for $x \in[0, X], X>0$, and consider investments $\left(x_{n}\right)_{n \in S}$ with $X_{N} \leq X$ and distribution $H$. Let $\widehat{H}$ be a mean-preserving spread of $H$ and $\left(\widehat{x}_{n}\right)_{n \in S}$ the investments induced by $\widehat{H}$. The firm's expected payoff under $\left(\widehat{x}_{n}\right)_{n \in S}$ is higher than that under $\left(x_{n}\right)_{n \in S}$.

For intuition, consider the example from the Introduction, with $F$ uniform over $[0,30]$ and $\theta=10 \%$. Suppose first that the firm raised capital from $N=3$ agents with $x_{1}=x_{2}=x_{3}=10$. By our results in the previous section and as can be seen in Figure 1, the firm's optimal scheme would then entail costs equal to $10(30 \%+15 \%+10 \%)=5.5$. Now suppose that two of these investors were "merged" into a single larger investor, so the firm raises capital from $N=2$ agents with $x_{1}=10$ and $x_{2}=20$. The firm's costs under an optimal scheme would then be lower, equal to $20(15 \%)+10(10 \%)=4$. The reason is that merging the agents reduces the strategic uncertainty: while each separate agent faces uncertainty about the investment decision of the other agent, the merged agent knows that she will invest her whole capital amount in the firm's project. This allows the firm to guarantee the same total investment at a lower risk premium.

Proposition 3 shows that this logic holds more generally. We find that any meanpreserving spread of the distribution of capital increases the firm's payoff. To see why this

\footnotetext{
${ }^{23}$ The function $H$ differs from a cumulative distribution function insofar as its maximum value is not 1 but $N$.
} 
is the case, consider capital amounts $\left(x_{n}\right)_{n \in S}$ with distribution $H$. Any mean-preserving spread $\widehat{H}$ can be obtained from $H$ by performing a finite sequence of transfers from smaller to larger investors (Rothschild and Stiglitz, 1970). We show that each such transfer makes the firm better off. Fixing an optimal permutation $\pi=\left(n_{1}, \ldots, n_{N}\right)$ under $\left(x_{n}\right)_{n \in S}$, a transfer from a small to a large investor allows the firm to move down the optimal return curve $\theta / F\left(X_{i}\right)$ more quickly and thus reduce its costs. Intuitively, the transfer lowers the required risk premium by increasing the self-insurance of the large investor. This implies that the firm's payoff under the induced amounts $\left(\widehat{x}_{n}\right)_{n \in S}$ is higher than that under $\left(x_{n}\right)_{n \in S}$ given optimal returns and the original permutation $\pi$. Clearly, changing to a permutation that is optimal under $\left(\widehat{x}_{n}\right)_{n \in S}$ can only raise the firm's payoff further. It follows that this operation always benefits the firm.

In the limit, the operation in Proposition 3 would concentrate all the capital of the agents in only one of them. In fact, if the firm raised capital from only one agent, this agent would face no strategic risk, and the firm would be able to raise the total capital $X_{N}$ by offering a net return under success equal to $\theta / F\left(X_{N}\right)$. The firm's costs in this case would be minimized and equal to $X_{N} \theta$. The firm's costs are higher when raising capital from multiple agents because of the coordination problem governing the agents' interaction. The price of coordination is the additional cost above $X_{N} \theta$ that the firm pays when dealing with $N>1$ agents, given by $\theta F\left(X_{N}\right) \sum_{i=1}^{N} x_{n_{i}^{*}}\left(\frac{1}{F\left(X_{i}\right)}-\frac{1}{F\left(X_{N}\right)}\right)$ for $X_{i}=\sum_{j=1}^{i} x_{n_{j}^{*}}$. Proposition 3 implies that the price of coordination is lower the more unequal is the distribution of agents' investments. Figure 2 provides an illustration using the example discussed above.

Proposition 3 has immediate implications on the feasibility of investment. Since a more unequal distribution of capital among the agents increases the firm's payoff from any given investment, such a distribution also reduces the minimum surplus $A$ that is required from a project for investment to be profitable. As a consequence, we find that a larger range of investments can be undertaken when the population of investors is more heterogeneous.

Returning to the firm's problem, the result in Proposition 3 also tells us what are the optimal investments $\left(x_{n}^{*}\right)_{n \in S}$ that the firm induces from the agents. For any given total investment $X_{N}$, we find that the firm raises as much capital as it can from the agents with the largest capital endowments. This solution yields the most unequal distribution over the agents' investments $\left(x_{n}\right)_{n \in S}$ that is feasible given the agents' endowments $\left(\bar{x}_{n}\right)_{n \in S}$, and so it is optimal by Proposition 3. 


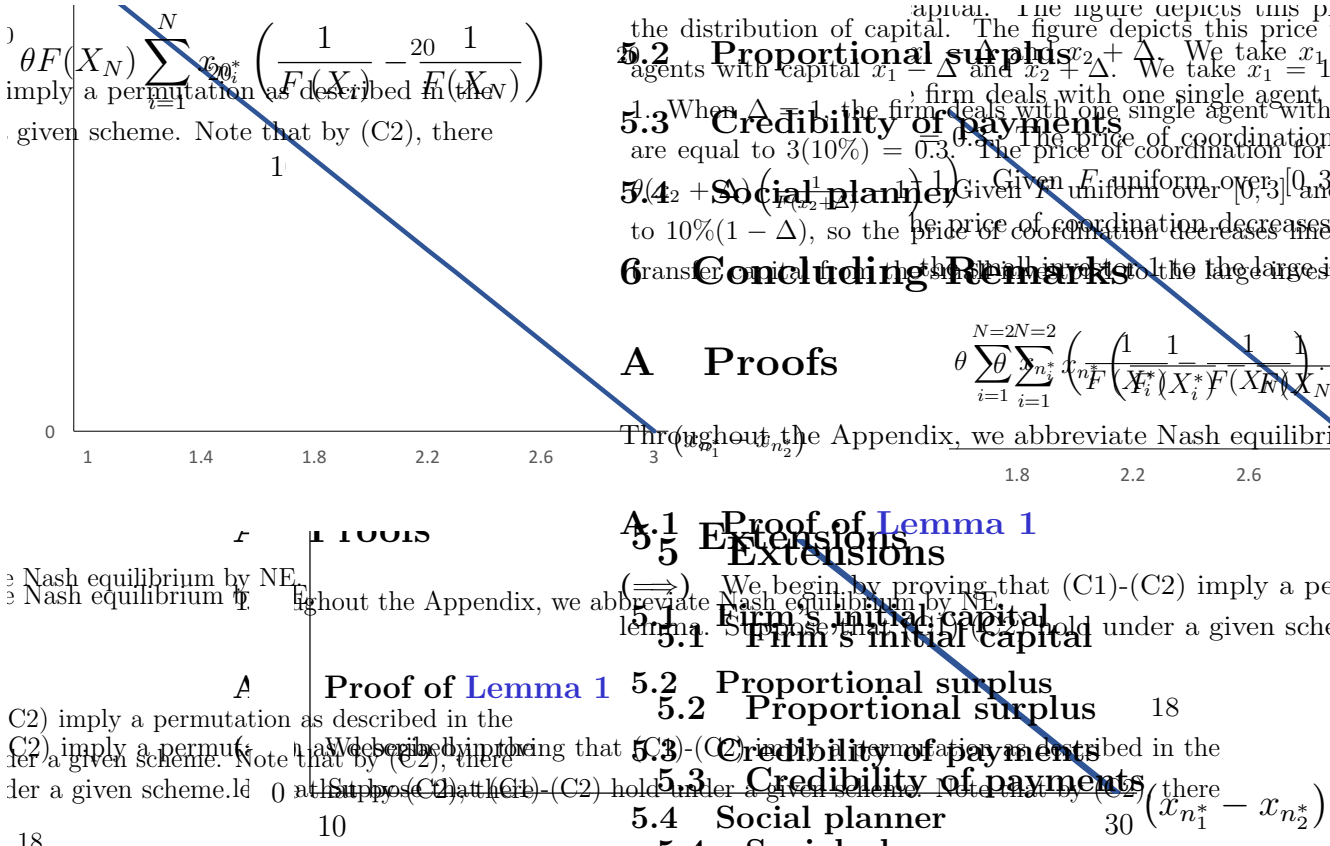

Figure 2: Price of coordination for $F$ uniform over [0,30], $\theta=10 \%$, and $N=2$ agents with aggregate capital $X_{2}=30$, as we increase $\left(x_{n_{1}^{*}}-x_{n_{2}^{*}}\right)$ from 10 to 30 .

Corollary 2. Suppose $1 / F(x)$ is convex for $x \in[0, X], X>0$, and agents' endowments satisfy $\sum_{n=1}^{N} \bar{x}_{n} \equiv \bar{X}_{N} \leq X$. Consider a permutation $\pi=\left(n_{1}, \ldots, n_{N}\right)$ that ranks the agents in decreasing endowment order, i.e. with $i \leq i^{\prime}$ if and only if $\bar{x}_{n_{i}} \geq \bar{x}_{n_{i^{\prime}}}$. For any given total investment $X_{N} \leq \bar{X}_{N}$, an optimal scheme specifies investments $\left(x_{n_{i}}^{*}\right)_{i \in S}$ satisfying

$$
x_{n_{i}}^{*}= \begin{cases}\bar{x}_{n_{i}} & \text { if } i<i^{*}, \\ x_{n_{i^{*}}}^{*} & \text { if } i=i^{*} \\ 0 & \text { otherwise }\end{cases}
$$

where $i^{*} \equiv \max \left\{i \in[0, N+1]: \sum_{i<i^{*}} \bar{x}_{n_{i}} \leq X_{N}\right\}$ and $x_{n_{i^{*}}}^{*} \equiv X_{N}-\sum_{i<i^{*}} \bar{x}_{n_{i}}$. Moreover, letting $X_{i}^{*} \equiv \sum_{j=1}^{i} x_{n_{j}}^{*}$, the optimal total investment $X_{N}^{*}$ then solves:

$$
\max _{X_{N} \in\left[0, \bar{X}_{N}\right]} V=\left(A-\theta \sum_{i=1}^{N} \frac{x_{n_{i}}^{*}}{F\left(X_{i}^{*}\right)}\right) F\left(X_{N}\right) .
$$

Note that the firm's scheme may imply differences among the agents not only in their net returns from investment but also in their access to investment opportunities. Specifically, if the total capital available $\bar{X}_{N}$ exceeds the amount $X_{N}$ that the firm raises, then the firm targets the largest investors in the set and excludes smaller investors from 
the project.

Given the optimal individual investments as a function of $X_{N}$, the second part of Corollary 2 completes our characterization of the firm's optimal scheme by solving for the optimal total investment $X_{N}^{*}$. The program in (6) follows directly from our characterization in Proposition 1 and Proposition 2.

\subsection{Distribution of returns}

Our last result concerns the relationship between the distribution of capital among the agents and the distribution of the agents' net investment returns. Consider an optimal scheme guaranteeing investments $\left(x_{n}\right)_{n \in S}$. By Proposition 1 and Proposition 2, the scheme specifies a permutation $\pi^{*}=\left(n_{1}^{*}, \ldots, n_{N}^{*}\right)$ ranking the agents in decreasing size order and yields each agent $n_{i}$ an expected net return $F\left(X_{N}\right) r_{i}^{*}$. Since $r_{i}^{*} \geq r_{i^{\prime}}^{*}$ for $i \leq i^{\prime}$, the range of net returns is equal to the difference between the largest and smallest investors' net returns, $F\left(X_{N}\right)\left(r_{1}^{*}-r_{N}^{*}\right)$. We find that if the distribution of investments becomes more unequal, the dispersion of net returns as measured by the range declines:

Proposition 4. Suppose $1 / F(x)$ is convex for $x \in[0, X], X>0$, and consider investments $\left(x_{n}\right)_{n \in S}$ with $X_{N} \leq X$ and distribution $H$. Let $\widehat{H}$ be a mean-preserving spread of $H$ and $\left(\widehat{x}_{n}\right)_{n \in S}$ the investments induced by $\widehat{H}$. The range of net returns offered by the firm under $\left(\widehat{x}_{n}\right)_{n \in S}$ is smaller than that under $\left(x_{n}\right)_{n \in S}$.

Recall that any mean-preserving spread $\widehat{H}$ can be obtained from the original distribution $H$ by performing a finite sequence of transfers from smaller to larger investors. To prove the proposition, we show that any such transfer keeps the smallest investor's net return unchanged (and equal to $\theta$ ) while reducing the largest investor's net return (strictly if the transfer increases this investor's capital). These effects apply regardless of whether the identities of the smallest and largest investors change, and they imply that the range of net returns becomes smaller. In this sense, we find that the firm's scheme is less discriminatory when the agents' capital amounts are more heterogeneous.

The example from the Introduction offers an illustration. For $F$ uniform over $[0,30]$ and $\theta=10 \%$, compare two agents with capital amounts $\left(x_{1}, x_{2}\right)=(10,20)$ against two agents with capital amounts $\left(\widehat{x}_{1}, \widehat{x}_{2}\right)=(6,24)$. Under an optimal scheme guaranteeing full investment, agent 1 and agent 2 receive expected net returns of $10 \%$ and $15 \%$ respectively in the former case, whereas in the latter case these expected net returns are $10 \%$ and $12.5 \%$. The range is therefore smaller under the more unequal distribution of capital: $(12.5-10) \%<(15-10) \%$. 
Of course, the range of agents' capital amounts is larger when capital is more unequally distributed. In the example, this range is $20-10$ under $\left(x_{1}, x_{2}\right)$ and $24-6$ under $\left(\widehat{x}_{1}, \widehat{x}_{2}\right)$. The net effect of heterogeneity on the range of final capital is thus unclear, as final capital holdings depend on both the agents' investments and their net returns. In the example, the range of final capital is larger under $\left(\widehat{x}_{1}, \widehat{x}_{2}\right): 24(1+12.5 \%)-6(1+10 \%)>$ $20(1+15 \%)-10(1+10 \%)$. More generally, either direction is possible depending on parameters. That is, perhaps surprisingly, we find that by reducing the dispersion of net returns, a more unequal distribution of initial capital can lead to a more equal distribution of final capital. ${ }^{24}$

\section{Firm's Initial Capital}

Our model has considered a firm which owns no initial capital, so any payments it offers to the agents must be self-financed by its project. In this section, we study how the firm's problem changes when the firm has some capital of its own. We show that our main qualitative results continue to hold, with larger investors receiving higher net returns than smaller ones. What is new is that the firm now uses its funds to insure part of the investment, and we are able to provide a characterization of the level of insurance offered to different investors depending on their size.

Suppose the firm has initial capital $W>0$ and wishes to raise an additional amount $X_{N}$ from the set $S$ of $N$ agents. Consider a scheme specifying investments $\left(x_{n}\right)_{n \in S}$ and returns $\left(r_{n}, k_{n}\right)_{n \in S}$, where without loss we take $x_{n}>0$ for each $n \in S$. The firm's budget constraint now requires that, for all profiles of agents' choices $\mathcal{Y}=\left(y_{1}, \ldots, y_{N}\right)$, the scheme satisfy

$$
\sum_{n=1}^{N} r_{n} y_{n} x_{n} \leq W+A \quad \text { and } \quad \sum_{n=1}^{N} k_{n} y_{n} x_{n} \leq W .
$$

If $W \geq \theta X_{N}$, the problem is trivial: the firm can offer net returns $\left(r_{n}, k_{n}\right)=(\theta, \theta)$ to each agent $n \in S$ and fund its project at the safe rate. As all the agents are given full insurance, there is no coordination problem among them. In what follows, we thus assume that the firm's capital is limited, satisfying $W<\theta X_{N}$.

The firm's problem is the same as that in $(\mathrm{P})$ but with the budget constraint given by $\left(\mathrm{BC}_{W}\right)$ above (and with the total investment in the project now including the firm's capital $W$ in addition to the capital $X_{N}$ raised from the agents). To solve this problem,

\footnotetext{
${ }^{24}$ For an example, take $F(x)=x^{5}$ for $x \in[0,1], \theta=10 \%$, and capital amounts $\left(x_{1}, x_{2}\right)=\left(\frac{1}{3}, \frac{2}{3}\right)$ and $\left(\widehat{x}_{1}, \widehat{x}_{2}\right)=\left(\frac{1}{4}, \frac{3}{4}\right)$. The range of final capital is 0.81 under $\left(x_{1}, x_{2}\right)$ and 0.79 under $\left(\widehat{x}_{1}, \widehat{x}_{2}\right)$.
} 
observe first that Lemma 1 continues to hold in this setting. The firm's scheme must thus specify a permutation $\pi=\left(n_{1}, \ldots, n_{N}\right)$ such that, for each $i \in S$, agent $n_{i}$ is willing to invest when agents $\left(n_{1}, \ldots, n_{i-1}\right)$ invest, no matter the rest. The key difference relative to the analysis of Section 3.1 is that the firm can now pay positive returns under failure, and hence, in principle, offer returns satisfying $k_{i}>r_{i}$ to some agent $n_{i} \in S$. Such an agent's expected payoff from investing with the firm would be decreasing in the other agents' investments. That is, unlike when $W=0$, inducing strategic substitutabiliy is now feasible.

Nevertheless, we are able to show that an optimal scheme for the firm induces strategic complementarities among all the agents. Suppose by contradiction that $k_{i}>r_{i}$ for some agent $n_{i} \in S$ in any optimal scheme. Such an agent's participation requires $k_{i}>\theta$, and so by $\left(\mathrm{BC}_{W}\right)$ and $W<\theta X_{N}$, there must exist $j \neq i$ with $k_{j}<\theta<r_{j}$. Furthermore, by analogous logic as in Section 3.1, agent $n_{i}$ must be indifferent over investing with the firm when all other agents invest, whereas agent $n_{j}$ must be indifferent conditioning on only agents $\left(n_{1}, \ldots, n_{j-1}\right)$ investing. Since agent $n_{i}$ then conditions on a weakly higher probability of success than agent $n_{j}$, we consider a perturbation that reduces $k_{i}$ and increases $r_{i}$ while at the same time increasing $k_{j}$ and reducing $r_{j}$. We show that this perturbation either contradicts the optimality of the original scheme or allows us to construct another optimal scheme which satisfies $r_{i} \geq k_{i}$ for all $i \in S$.

Using the strategic complementaries, we obtain the following characterization:

Proposition 5. Consider the firm's problem with initial capital $W>0$. Suppose $1 / F(x)$ is convex for $x \in[0, X], X>0$, and there exists an optimal scheme guaranteeing investments $\left(x_{n}\right)_{n \in S}$ with $X_{N} \leq X$. Then an optimal such scheme specifies a permutation $\pi^{*}=\left(n_{1}^{*}, \ldots, n_{N}^{*}\right)$ satisfying

$$
x_{n_{1}^{*}} \geq \ldots \geq x_{n_{N}^{*}}
$$

and returns $\left(r_{i}^{*}, k_{i}^{*}\right)_{i \in S}$ satisfying

$$
k_{i}^{*}=\frac{\min \left\{\theta x_{n_{i}^{*}}, W_{i}\right\}}{x_{n_{i}^{*}}} \text { and } r_{i}^{*}=\frac{\theta-k_{i}^{*}\left(1-F\left(W+X_{i}\right)\right)}{F\left(W+X_{i}\right)}
$$

where $X_{i}=\sum_{j=1}^{i} x_{n_{j}^{*}}, W_{N} \equiv W$, and $W_{i} \equiv \max \left\{W-\sum_{j=i+1}^{N} k_{j}^{*} x_{n_{j}^{*}}, 0\right\}$ for $i \in\{1, \ldots, N-1\}$.

An optimal scheme for the firm includes full-insurance contracts, with returns under success and failure equal to the safe rate $\theta$. That is, we find that the firm uses its initial capital $W$ to fully insure some of the capital $X_{N}$ that it raises from the agents. Since 
$W$ is limited, only an amount of capital $W / \theta$ can be insured. Once $W$ is depleted, the firm faces the same problem that we solved in the previous sections, and hence it guarantees investment using a scheme analogous to that characterized in Proposition 1 and Proposition 2.

Proposition 5 shows that the smallest investors are the ones who receive insurance. The intuition is simple. The firm's cost of fully insuring the portion of capital $W / \theta$ is equal to $W$ and thus independent of how this capital is distributed among the agents. In contrast, the firm's cost of raising the additional capital $X_{N}-W / \theta$ does depend on its distribution: by Proposition 3, this cost is minimized when $X_{N}-W / \theta$ is raised from the largest investors. Consequently, it follows that it is optimal for the firm to raise the fully insured portion $W / \theta$ from the smallest investors.

The characterization in Proposition 5 shows that our results in Section 3 and Section 4 are robust to the firm owning initial capital. ${ }^{25}$ In addition, this characterization offers predictions on the levels of risk afforded to investors of different size. Interestingly, empirical studies find that large investors hold riskier portfolios than small investors, and some of the explanations discussed in the literature include capital market imperfections and investors' risk aversion declining with wealth (see Carroll, 2000). ${ }^{26}$ We contribute to this discussion from a different perspective, that of optimal design. Proposition 5 indeed predicts a high-risk, high-return investment for large investors and a low-risk, low-return investment for small investors. Here, however, the distinction arises as an optimal solution to the firm's problem of raising capital in the presence of strategic risk.

\section{Discussion}

Below we discuss some applications and extensions of our model and results.

Applications. We have formulated our problem in the context of a firm that raises capital to fund a project. There are various examples that may fit this description. As mentioned, our results resonate with evidence from private equity investments. The project in our model could also concern the building of a property to which agents contribute with purchase commitments, or fund-raising for a charity as in Andreoni (1998). We next discuss some further applications that relate to other literatures.

\footnotetext{
${ }^{25}$ Note that the smallest investors who receive full insurance also receive a lower net return on their investment compared to other investors, since $\theta \leq F\left(W+X_{N}\right) r_{i}^{*}+\left(1-F\left(W+X_{N}\right)\right) k_{i}^{*}$ for any $i \in S$.

${ }^{26}$ Capital market imperfections may cause entrepreneurs to finance their activities with their own capital and to earn a high return on their investments.
} 
Exclusive contracts: A number of influential papers study how an incumbent firm may coordinate buyers on signing exclusive dealing contracts (see Rasmusen, Ramseyer and Wiley, 1991; Innes and Sexton, 1994; Segal and Whinston, 2000). Our analysis can be applied to this question. Consider an incumbent monopolist offering exclusive dealing contracts to buyers of different size, namely who differ in the number of units that they demand. ${ }^{27}$ A potential entrant enters the market only if the total demand that has contracted with the monopolist is below a stochastic threshold, and the monopolist offers prices contingent on entry to guarantee a given total demand. Our results suggest that under certain conditions on the threshold distribution, the monopolist will offer lower unit prices to larger buyers compared to smaller ones. Moreover, the more heterogeneous the buyer population, the higher the monopolist's incentive to offer exclusive dealing contracts to fight market entry.

Joint task: Consider a team incentive problem similar to that in Winter (2004) but allowing for heterogeneity. A principal contracts with multiple agents who can contribute towards a joint task. Agents differ in their ability, with more skilled agents being able to make larger contributions than less skilled ones. Suppose that the probability of completing the joint task is increasing in the sum of agents' contributions, and the principal offers rewards contingent on task completion in order to guarantee a level of participation. Applying our results to this setting suggests that optimal rewards will be convex: the principal compensates agents with high ability more than proportionally relative to those with lower ability.

Bank runs: A sizable literature studies bank runs and how to prevent them. Consider a simple setting in which $N$ agents have their funds deposited in a bank and can withdraw them at any time. Suppose there is a random threshold such that if the total withdrawal exceeds it, a bank run occurs and the bank collapses. To exclude a run, the bank can offer depositors collateral (to be paid in the case of a run) or a higher interest rate on deposits (absent a run). A conjecture that can be derived from our analysis is that large depositors will be treated more favorably than small ones even on a per-dollar basis, whether it is collateral or an increased interest rate that is used to prevent the run.

Social planner and policy implications. We have solved the problem of a firm that seeks to maximize its profits while guaranteeing a unique outcome. We point out here that our results also have implications for a planner who internalizes agents' welfare.

\footnotetext{
${ }^{27}$ Note that due to compatibility and cost considerations, these demands are often indivisible.
} 
Consider the problem of a planner who maximizes the probability of project success, subject to budget and unique implementation constraints as those in program $(\mathrm{P})$. Because the budget constraint requires limiting the cost of raising capital, the solution to this problem coincides with that of the firm when the budget constraint is tight enough, namely when the surplus $A$ from project success is sufficiently small. Specifically, the planner may have to give higher net returns to larger investors compared to smaller investors in order to be able to self-finance the investment in the project. Furthermore, the planner may benefit from a more unequal distribution of capital among the agents, as such a distribution allows to reduce costs and make the investment viable.

Of course, things change if we take different social welfare functions, and in particular if we consider a concern for inequality. Our analysis shows that the need to address strategic risk gives rise to an important tradeoff between equality and efficiency.

Policy responses aimed at limiting inequality should support small investors, who we find will be either excluded from investing or given worse terms than others. Intermediaries that bundle the capital of many small private investors into a single larger investment may help in this regard, provided that they do not extract the entire additional surplus by charging high fees. Regulators can also generate instruments to facilitate coordination. For example, it may be possible to promote platforms where small investors can make commitments to invest that are legally binding but contingent on a minimum total investment. Such instruments would reduce the strategic risk which, we have shown, drives inequality.

Threshold distribution. Our analysis has focused on situations in which the distribution $F$ of the investment threshold satisfies the condition of $1 / F(x)$ being convex. As noted in Section 3.2, $1 / F(x)$ cannot be globally concave, and it is indeed globally convex for most commonly used distribution functions. Yet, it is worth considering how our results would change if the condition on $F$ is not met.

Given capital amounts $\left(x_{n}\right)_{n \in S}$, suppose $1 / F(x)$ is concave over the whole relevant range, namely for $x \in\left[\min \left\{x_{n} \mid n \in S\right\}, X_{N}\right]$. Then our results in Proposition 2 would be reversed: given optimal returns $\left(r_{i}^{*}, k_{i}^{*}\right)_{i \in S}$ as characterized in Proposition 1, we would find that an optimal permutation $\pi^{*}=\left(n_{1}^{*}, \ldots, n_{N}^{*}\right)$ ranks the agents in increasing as opposed to decreasing size order. The intuition is the same as in Proposition 2 but also reversed: the firm benefits from placing large investors in the permutation according to when the risk premium drops most sharply with investment, and if $1 / F(x)$ is concave, this occurs at the end of the permutation, when $X_{i}=\sum_{j=1}^{i} x_{n_{j}}$ is largest. The implication 
is that larger investors would now receive lower net returns than smaller investors, as opposed to the case in which $1 / F(x)$ is convex. The contrasting results that we obtain in the two cases offer predictions that could be empirically tested.

Regarding the analysis in Section 4, we maintained the assumption of $1 / F(x)$ convex throughout that section for consistency with our results in Section 3. However, our results on the distribution of capital in Section 4 are more general. In fact, if $1 / F(x)$ is concave over the whole relevant range, one can follow the same proof strategy used for Proposition 3 to verify that the result sill applies, namely that the firm benefits from distributions of capital which are more unequal.

Proportional surplus. Our model has assumed that project success yields a fixed surplus $A>0$, and only the probability of success varies with the amount of capital invested in the project. More generally, the surplus from project success may also be a function of the investment. Consider a simple case in which success yields a surplus $R x$ if capital $x$ is invested in the project, for some $R>\theta$. Given a scheme specifying investments $\left(x_{n}\right)_{n \in S}$ and returns $\left(r_{n}, k_{n}\right)_{n \in S}$, the firm's budget constraint then requires that, for all profiles $\mathcal{Y}=\left(y_{1}, \ldots, y_{N}\right)$,

$$
\sum_{n=1}^{N} r_{n} y_{n} x_{n} \leq \sum_{n=1}^{N} R y_{n} x_{n} \quad \text { and } \quad \sum_{n=1}^{N} k_{n} y_{n} x_{n} \leq 0
$$

Relative to the original budget constraint (BC), this constraint places further restrictions on the firm's scheme. In fact, note that given $R,\left(\mathrm{BC}_{R}\right)$ implies $(\mathrm{BC})$ under a fixed surplus $A_{R} \equiv R X_{N}$, as both constraints require that the sum of payments under success do not exceed this amount. But $\left(\mathrm{BC}_{R}\right)$ adds restrictions, by requiring that the payment to any agent under success be no larger than the surplus generated by the project when only such an agent has invested. That is, the firm's budget constraint now requires $\max _{n \in S} r_{n} \leq R$.

Despite this difference, we can show that the analysis of Section 3 continues to apply to this setting. Specifically, given $R$, consider the firm's problem in $(\mathrm{P})$ when project success yields a fixed surplus equal to $A_{R}$. As just explained, this is a relaxed problem relative to the firm's proportional surplus problem that is subject to $\left(\mathrm{BC}_{R}\right)$. Hence, it follows that if the solution to $(\mathrm{P})$ described in Proposition 1 and Proposition 2 satisfies $\left(\mathrm{BC}_{R}\right)$ - namely, if this solution specifies $r_{n_{1}^{*}}^{*} \leq R$ - then it is also a solution to the firm's proportional surplus problem. Moreover, note that among all schemes guaranteeing investments $\left(x_{n}\right)_{n \in S}$ subject to (BC), the solution to $(\mathrm{P})$ minimizes the highest return 
that the firm has to pay to any agent $n \in S$ under success. Therefore, if the solution described in Proposition 1 and Proposition 2 specifies $r_{n_{1}^{*}}^{*}>R$, no scheme can guarantee investments $\left(x_{n}\right)_{n \in S}$ while satisfying $\left(\mathrm{BC}_{R}\right)$.

\section{A Proofs}

Throughout the Appendix, we abbreviate Nash equilibrium by NE.

\section{A.1 Proof of Lemma 1}

As defined in Section 3.1, denote the aggregate capital of the first $i$ agents in a permutation $\pi=\left(n_{1}, \ldots, n_{N}\right)$ by $X_{i} \equiv \sum_{j=1}^{i} x_{n_{j}}$.

$(\Longrightarrow)$ We begin by proving that $(\mathrm{C} 1)-(\mathrm{C} 2)$ imply a permutation as described in the lemma. Suppose that $(\mathrm{C} 1)-(\mathrm{C} 2)$ hold under a given scheme. Note that by $(\mathrm{C} 2)$, there must exist an agent $n_{1}$ who is willing to invest with the firm when no other agent does. If this was not true, there would be a NE in which no agent invests and no agent is indifferent between investing and not, contradicting $(\mathrm{C} 2)$. Hence, we have:

$$
r_{1} F\left(X_{1}\right)+k_{1}\left(1-F\left(X_{1}\right)\right) \geq \theta \text {. }
$$

Additionally, by (C1), agent $n_{1}$ must be willing to invest with the firm when all other agents do. Otherwise, there would not be a NE in which all agents invest with the firm, contradicting (C1). Hence, we also have:

$$
r_{1} F\left(X_{N}\right)+k_{1}\left(1-F\left(X_{N}\right)\right) \geq \theta
$$

For any set of agents $S_{I} \subseteq S \cup \emptyset$, let $X\left(S_{I}\right) \equiv \sum_{i \in S_{I}} x_{n_{i}}$ be the aggregate capital of the agents in $S_{I}$. Since $F\left(X_{1}\right) \leq F\left(X_{1}+X\left(S_{I}\right)\right) \leq F\left(X_{N}\right)$ for $S_{I} \subseteq\{2, \ldots, N\} \cup \emptyset$, equations (7) and (8) imply

$$
r_{1} F\left(X_{1}+X\left(S_{I}\right)\right)+k_{1}\left(1-F\left(X_{1}+X\left(S_{I}\right)\right)\right) \geq \theta
$$

for all $S_{I} \subseteq\{2, \ldots, N\} \cup \emptyset$. Therefore, agent $n_{1}$ is willing to invest with the firm no matter what the other agents do.

We now proceed by induction: for any $i \in\{2, \ldots, N-1\}$, suppose that there is an agent $n_{i}$ who is willing to invest with the firm if agents $\left(n_{1}, \ldots, n_{i-1}\right)$ invest, regardless 
of what the other agents do. Then there must be an agent $n_{i+1}$ who is willing to invest with the firm if agents $\left(n_{1}, \ldots, n_{i}\right)$ invest and the other agents do not. Otherwise, there would be a NE in which agents $\left(n_{1}, \ldots, n_{i}\right)$ invest with the firm, agents $\left(n_{i+1}, \ldots, n_{N}\right)$ do not, and no non-investing agent is indifferent between investing and not, contradicting (C2). Thus, we have

$$
r_{i+1} F\left(X_{i+1}\right)+k_{i+1}\left(1-F\left(X_{i+1}\right)\right) \geq \theta
$$

Moreover, by (C1), agent $n_{i+1}$ must also be willing to invest with the firm when all other agents do:

$$
r_{i+1} F\left(X_{N}\right)+k_{i+1}\left(1-F\left(X_{N}\right)\right) \geq \theta \text {. }
$$

Since $F\left(X_{i+1}\right) \leq F\left(X_{i+1}+X\left(S_{I}\right)\right) \leq F\left(X_{N}\right)$ for $S_{I} \subseteq\{i+2, \ldots, N\} \cup \emptyset$, equations (9) and (10) imply

$$
r_{i+1} F\left(X_{i+1}+X\left(S_{I}\right)\right)+k_{i+1}\left(1-F\left(X_{i+1}+X\left(S_{I}\right)\right)\right) \geq \theta
$$

for all $S_{I} \subseteq\{i+2, \ldots, N\} \cup \emptyset$. Therefore, agent $n_{i+1}$ is willing to invest with the firm if agents $\left(n_{1}, \ldots, n_{i}\right)$ invest with the firm, regardless of what the other agents do.

$(\Longleftarrow)$ We next prove that a permutation as described in the lemma implies $(\mathrm{C} 1)-(\mathrm{C} 2)$. First, note that since each agent $n_{i} \in S$ is willing to invest if $\left(n_{1}, \ldots, n_{i-1}\right)$ invest no matter what the rest does, it must be that each agent $n_{i}$ is willing to invest when all other agents invest. Hence, there exists a NE in which all agents invest, yielding $(\mathrm{C} 1)$.

Next, suppose by contradiction that (C2) does not hold, namely there exists a NE in which some agents do not invest with the firm and all such agents strictly prefer not to invest. Call the set of non-investing agents $S_{N I}$. We claim that if all agents $n_{i} \in S_{N I}$ strictly prefer not to invest, then $S_{N I}$ must be empty. Clearly, $n_{1}$ cannot be in $S_{N I}$, as $n_{1}$ is willing to invest with the firm no matter what the other agents do. So $n_{1}$ must be in the set of agents who invest, call it $S_{I}$. Now proceed by induction: for any $i \in\{2, \ldots, N-1\}$, suppose that agents $\left(n_{1}, \ldots, n_{i}\right)$ are in $S_{I}$. Then by the permutation stated in the lemma, agent $n_{i+1}$ is willing to invest with the firm, and thus she cannot be in $S_{N I}$ either. It follows that no agent is in $S_{N I}$. Therefore, in any NE in which $S_{N I}$ is nonempty, at least one agent in $S_{N I}$ is willing to invest, yielding (C2). 


\section{A.2 Proof of Proposition 1}

We begin by proving the first part of the proposition. By Lemma 1, any optimal scheme

specifies some permutation $\pi=\left(n_{1}, \ldots, n_{N}\right)$ and returns $\left(r_{i}, k_{i}\right)_{i \in S}$ which satisfy, for each $i \in S$ and each $j \in\{i, \ldots, N\}$,

$$
r_{i} F\left(X_{j}\right)+k_{i}\left(1-F\left(X_{j}\right)\right) \geq \theta
$$

As argued in the text, the firm's budget constraint (BC) requires $k_{i} \leq 0$ for each $i \in S$. Given this and $\theta>0$, equation (11) then requires $r_{i}>0$ for each $i \in S$. It follows that $r_{i}>0 \geq k_{i}$ for each $i \in S$, and thus the left-hand side of (11) is increasing in $F\left(X_{j}\right)$. Since $F\left(X_{j}\right)$ is increasing in $j$, it follows that (11) holds for each $i \in S$ and each $j \in\{i, \ldots, N\}$ if and only if, for each $i \in S$,

$$
r_{i} F\left(X_{i}\right)+k_{i}\left(1-F\left(X_{i}\right)\right) \geq \theta
$$

We show that optimality requires (12) to hold with equality for each $i \in S$. Suppose by contradiction that there is an optimal scheme under which (12) holds as a strict inequality for some $i^{\prime} \in S$. Then consider a perturbation in which we reduce $r_{i^{\prime}}$ by $\varepsilon>0$ arbitrarily small while keeping all other returns unchanged. Since (12) was a strict inequality for $i^{\prime}$, this constraint continues to be satisfied for all $i \in S$. It is also clear that the budget constraint $(\mathrm{BC})$ is relaxed by the perturbation. Moreover, note that the firm's expected payoff is

$$
V=\left(A-\sum_{i=1}^{N} r_{i} x_{n_{i}}\right) F\left(X_{N}\right)-\sum_{i=1}^{N} k_{i} x_{n_{i}}\left(1-F\left(X_{N}\right)\right)
$$

which is decreasing in $r_{i}$ for any $i \in S$. Therefore, we obtain that the perturbation increases the firm's expected payoff while preserving incentives and the firm's budget constraint, and thus the original scheme cannot be optimal.

We next prove the second part of the proposition. By the claims above, any optimal scheme specifies some permutation $\pi=\left(n_{1}, \ldots, n_{N}\right)$ and returns $\left(r_{i}, k_{i}\right)_{i \in S}$ satisfying

$$
r_{i} F\left(X_{i}\right)+k_{i}\left(1-F\left(X_{i}\right)\right)=\theta
$$

for each $i \in S$. We show that it is optimal to set $k_{i}=0$ for each $i \in S$, which combined with (14) implies $r_{i}=\theta / F\left(X_{i}\right)$ for each $i \in S$. Suppose by contradiction that this is not 
the case, i.e. any optimal scheme has $k_{i^{\prime}}<0$ for some $i^{\prime} \in S$. (Recall that by the firm's budget constraint, $k_{i} \leq 0$ for all $i \in S$.) Then consider the following perturbation: for any such $i^{\prime}$, we increase $k_{i^{\prime}}$ by $\varepsilon>0$ arbitrarily small and reduce $r_{i^{\prime}}$ by $\varepsilon \eta_{i^{\prime}}$, where

$$
\eta_{i^{\prime}} \equiv \frac{1-F\left(X_{i^{\prime}}\right)}{F\left(X_{i^{\prime}}\right)}
$$

Since we had $k_{i^{\prime}}<0$, the perturbed scheme continues to satisfy the firm's budget constraint (BC). Moreover, by construction, the left-hand side of (14) is unchanged by the perturbation, so the agents' incentives are preserved. Finally, note that the perturbation changes the firm's expected payoff $V$ in (13) by

$$
\varepsilon \frac{\left(F\left(X_{N}\right)-F\left(X_{i^{\prime}}\right)\right)}{F\left(X_{i^{\prime}}\right)}
$$

which is positive (and strictly positive if $i^{\prime} \in\{1, \ldots, N-1\}$ ). Therefore, the perturbation increases the firm's expected payoff while preserving incentives and the budget constraint. Since we can perform this perturbation whenever $k_{i}<0$ for some $i \in S$, this contradicts the assumption that an optimal scheme with $k_{i}=0$ for each $i \in S$ does not exist.

Finally, we prove that if an optimal scheme exists, there exists an optimal scheme specifying some permutation $\pi=\left(n_{1}, \ldots, n_{N}\right)$ and returns $\left(r_{i}^{*}, k_{i}^{*}\right)=\left(\theta / F\left(X_{i}\right), 0\right)$ for each $i \in S$. As shown above, any optimal scheme specifies some permutation $\pi=$ $\left(n_{1}, \ldots, n_{N}\right)$ and returns $\left(r_{i}, k_{i}\right)_{i \in S}$ such that (14) holds for each $i \in S$. It is clear that for each agent $n_{i}$, the return $r_{i}$ that satisfies this binding participation constraint is decreasing in $k_{i}$. Thus, given a permutation $\pi$, setting $k_{i}$ as high as possible for each $i \in S$, subject to (BC), minimizes the firm's costs under success, $\sum_{i=1}^{N} r_{i} x_{n_{i}}$. It follows that setting $k_{i}=0$ for each $i \in S$ maximally relaxes the firm's budget constraint. As we have shown that setting $\left(r_{i}^{*}, k_{i}^{*}\right)=\left(\theta / F\left(X_{i}\right), 0\right)$ for some permutation $\pi$ is optimal subject to the budget constraint, this proves the claim.

\section{A.3 Proof of Proposition 2}

Assume that $1 / F(x)$ is convex for all $x \in\left[0, X_{N}\right]$. We proceed in two steps.

Step 1. Define

$$
\Psi(a, b, c) \equiv \frac{1}{c}\left(\frac{1}{F(a+b)}-\frac{1}{F(a+b+c)}\right)-\frac{1}{b}\left(\frac{1}{F(a+c)}-\frac{1}{F(a+b+c)}\right) .
$$


We show that for any $a \geq 0$ and $b>c>0$ satisfying $a+b+c \leq X_{N}$,

$$
\Psi(a, b, c) \leq 0
$$

To prove this claim, observe that

$$
\Psi(a, b, c)=\frac{1}{c} \int_{b}^{b+c} \frac{F^{\prime}(a+z)}{(F(a+z))^{2}} d z-\frac{1}{b} \int_{c}^{b+c} \frac{F^{\prime}(a+z)}{(F(a+z))^{2}} d z
$$

Define $\psi(\widetilde{z})=\frac{c \tilde{z}+b^{2}-c^{2}}{b}$. Note that $\psi$ is linear with $\psi(c)=b, \psi(b+c)=b+c$, and $\psi^{\prime}(\widetilde{z})=\frac{c}{b}$. Hence, a change of variables yields:

$$
\Psi(a, b, c)=\frac{1}{b} \int_{c}^{b+c}\left(\frac{F^{\prime}(a+\psi(\widetilde{z}))}{\left(F(a+\psi(\widetilde{z}))^{2}\right.}-\frac{F^{\prime}(a+\widetilde{z})}{(F(a+\widetilde{z}))^{2}}\right) d \widetilde{z}
$$

Note that given $b>c, \psi(\widetilde{z}) \geq \widetilde{z}$ for all $\widetilde{z}$ in the integration region. Given $a \geq 0$ and $a+b+c \leq X_{N}$, the assumption that $1 / F(x)$ is convex for all $x \in\left[0, X_{N}\right]$ then implies that the integrand in (17) is (weakly) negative. The claim follows.

Step 2. By Step 1, (16) holds for any $a \geq 0$ and $b>c>0$ satisfying $a+b+c \leq X_{N}$. Using (15), this inequality can be rewritten as

$$
\frac{b}{F(a+b)}+\frac{c}{F(a+b+c)} \leq \frac{c}{F(a+c)}+\frac{b}{F(a+b+c)}
$$

We now show that there is an optimal permutation $\pi^{*}=\left(n_{1}^{*}, \ldots, n_{N}^{*}\right)$ satisfying

$$
x_{n_{1}^{*}} \geq \ldots \geq x_{n_{N}^{*}}
$$

Suppose that some permutation $\pi=\left(n_{1}, \ldots, n_{N}\right)$ is optimal. If $\pi$ satisfies (19), we are done. Suppose instead that (19) is not satisfied. Take the lowest index $j<N$ for which $x_{n_{j}}<x_{n_{j+1}}$. We perform a perturbation in which we swap agents $n_{j}$ and $n_{j+1}$. Note that this swap has no effect on $X_{i}$ for any $i<j$ or $i>j+1$. Hence, the perturbation only affects the $j$ th and $(j+1)$ th terms of the sum in the firm's costs in $(5)$. Under the original permutation, these terms sum to:

$$
\frac{x_{n_{j}}}{F\left(X_{j-1}+x_{n_{j}}\right)}+\frac{x_{n_{j+1}}}{F\left(X_{j-1}+x_{n_{j}}+x_{n_{j+1}}\right)}
$$


The perturbation changes the sum of these terms to:

$$
\frac{x_{n_{j+1}}}{F\left(X_{j-1}+x_{n_{j+1}}\right)}+\frac{x_{n_{j}}}{F\left(X_{j-1}+x_{n_{j}}+x_{n_{j+1}}\right)}
$$

Letting $a=X_{j-1}, b=x_{n_{j+1}}$, and $c=x_{n_{j}}$, it follows from (18) that the sum in (21) is no larger than the sum in (20). Therefore, the perturbation (weakly) reduces the firm's costs and thus increases the firm's expected payoff. Note that we can proceed by performing this perturbation for the next pair of agents with (higher) indices $(i, i+1)$ such that $x_{n_{i}}<x_{n_{i+1}}$, repeating until the permutation satisfies (19). Since each perturbation increases the firm's expected payoff and the original permutation was optimal, we obtain that a permutation satisfying (19) is optimal.

\section{A.4 Proof of Proposition 3}

The distribution $\widehat{H}$ can be obtained from the original distribution $H$ by performing a finite sequence of capital transfers from small to large investors (Rothschild and Stiglitz, 1970). Thus, it suffices to show that each such transfer makes the firm better off. Without loss of generality, we can consider the first such transfer. Let the permutation $\pi=\left(n_{1}, \ldots, n_{N}\right)$ be optimal under $\left(x_{n}\right)_{n \in S}$. Take any two agents $n_{j}$ and $n_{\ell}$ where $j<\ell$ and, thus, $x_{n_{j}} \geq x_{n_{\ell}}$. For any $\Delta \in\left(0, x_{n_{\ell}}\right]$, let $\left(\widehat{x}_{n}\right)_{n \in S}$ be the result of transferring $\Delta$ units of capital from agent $n_{\ell}$ to agent $n_{j}$. We will show that the firm's minimized costs under $\left(\widehat{x}_{n}\right)_{n \in S}$ are lower than its minimized costs under $\left(x_{n}\right)_{n \in S}$ when keeping the permutation $\pi$ unchanged. Since the transfer does not change the probability of project success (as it does not affect the aggregate capital of the agents), it will follow that the firm's expected payoff under $\left(\widehat{x}_{n}\right)_{n \in S}$ is higher than that under $\left(x_{n}\right)_{n \in S}$ when keeping the permutation $\pi$ unchanged. Clearly, changing to a permutation that is optimal under $\left(\widehat{x}_{n}\right)_{n \in S}$ can only increase the firm's payoff from these investments further, so this is sufficient to prove the claim.

To show that the transfer from agent $n_{\ell}$ to agent $n_{j}$ reduces the firm's costs when keeping the permutation unchanged, note first that the costs from returns paid to agents $n_{i}$ with rank $i<j$ and $i>\ell$ are unaffected. The change in the firm's minimized costs in (5), divided by the constant $\theta>0$, is thus equal to

$$
\frac{\Delta}{F\left(X_{j}+\Delta\right)}-\frac{\Delta}{F\left(X_{\ell}\right)}-\sum_{i=j}^{\ell-1}\left[\frac{x_{n_{i}}}{F\left(X_{i}\right)}-\frac{x_{n_{i}}}{F\left(X_{i}+\Delta\right)}\right] .
$$


Replacing $F\left(X_{j}+\Delta\right)$ by $F\left(X_{j}\right)$ and $x_{n_{i}}$ by $x_{n_{i+1}},(22)$ is no larger than

$$
\frac{\Delta}{F\left(X_{j}\right)}-\frac{\Delta}{F\left(X_{\ell}\right)}-\sum_{i=j}^{\ell-1} x_{n_{i+1}}\left[\frac{1}{F\left(X_{i}\right)}-\frac{1}{F\left(X_{i}+\Delta\right)}\right]
$$

This expression can be rewritten as

$$
\Delta \sum_{i=j}^{\ell-1} x_{n_{i+1}} \Lambda_{i}
$$

where

$$
\begin{aligned}
\Lambda_{i} & =\frac{1}{x_{n_{i+1}}}\left[\frac{1}{F\left(X_{i}\right)}-\frac{1}{F\left(X_{i}+x_{n_{i+1}}\right)}\right]-\frac{1}{\Delta}\left[\frac{1}{F\left(X_{i}\right)}-\frac{1}{F\left(X_{i}+\Delta\right)}\right] \\
& =\frac{1}{x_{n_{i+1}}} \int_{X_{i}}^{X_{i}+x_{n_{i+1}}} \frac{F^{\prime}(z)}{(F(z))^{2}} d z-\frac{1}{\Delta} \int_{X_{i}}^{X_{i}+\Delta} \frac{F^{\prime}(z)}{(F(z))^{2}} d z
\end{aligned}
$$

Define $\psi(\widetilde{z})=\frac{x_{n_{i+1}} \widetilde{z}-X_{i}\left(x_{n_{i+1}}-\Delta\right)}{\Delta}$. Note that $\psi$ is linear with $\psi\left(X_{i}\right)=X_{i}, \psi\left(X_{i}+\Delta\right)=$ $X_{i}+x_{n_{i+1}}$, and $\psi^{\prime}(\widetilde{z})=\frac{x_{n_{i+1}}}{\Delta}$. Hence, a change of variables yields:

$$
\Lambda_{i}=\frac{1}{\Delta} \int_{X_{i}}^{X_{i}+\Delta}\left(\frac{F^{\prime}(\psi(\widetilde{z}))}{(F(\psi(\widetilde{z})))^{2}}-\frac{F^{\prime}(\widetilde{z})}{(F(\widetilde{z}))^{2}}\right) d \widetilde{z}
$$

Note that since $\Delta \leq x_{n_{\ell}}$ and $x_{n_{\ell}} \leq x_{n_{i+1}}$ for all $j \leq i \leq \ell-1$, we have $\Delta \leq x_{n_{i+1}}$ for all $j \leq i \leq \ell-1$. Thus, one can verify that $\psi(\widetilde{z}) \geq \widetilde{z}$ for all $\widetilde{z}$ in the integration region and $j \leq i \leq \ell-1$. Given $X_{i} \geq 0$ and $X_{i}+x_{n_{i+1}} \leq X_{N}$ for all $j \leq i \leq \ell-1$, the assumption that $1 / F(x)$ is convex for all $x \in\left[0, X_{N}\right]$ then implies that the integrand in (23) is (weakly) negative. It follows that $\Lambda_{i} \leq 0$ for all $j \leq i \leq \ell-1$ and thus (22) is no larger than a (weakly) negative number. The claim follows.

\section{A.5 Proof of Proposition 4}

The distribution $\widehat{H}$ can be obtained from the original distribution $H$ by performing a finite sequence of capital transfers from small to large investors (Rothschild and Stiglitz, 1970). Thus, it suffices to show that each such transfer weakly reduces the range of net returns. Denote the original investments by $\left(x_{n}\right)_{n \in S}$ and the resulting investments following a transfer by $\left(\widehat{x}_{n}\right)_{n \in S}$. Let $\pi=\left(n_{1}, \ldots, n_{N}\right)$ and $\widehat{\pi}=\left(\widehat{n}_{1}, \ldots, \widehat{n}_{N}\right)$ be permutations 
that rank the agents in decreasing size order under $\left(x_{n}\right)_{n \in S}$ and $\left(\widehat{x}_{n}\right)_{n \in S}$ respectively, where we consider only agents with strictly positive amounts of capital. The smallest investor's expected net return is the same under $\left(x_{n}\right)_{n \in S}$ and $\left(\widehat{x}_{n}\right)_{n \in S}$, as it is equal to $F\left(X_{N}\right) \frac{\theta}{F\left(X_{N}\right)}=\theta$ regardless of how $X_{N}$ is distributed among the agents. The largest investor's expected net return is equal to $F\left(X_{N}\right) \frac{\theta}{F\left(x_{n_{1}}\right)}$ under $\left(x_{n}\right)_{n \in S}$ and $F\left(X_{N}\right) \frac{\theta}{F\left(\widehat{x}_{\widehat{n}_{1}}\right)}$ under $\left(\widehat{x}_{n}\right)_{n \in S}$. Note that since $\left(\widehat{x}_{n}\right)_{n \in S}$ is the result of a transfer from a smaller to a larger investor, $\widehat{x}_{\widehat{n}_{1}} \geq x_{n_{1}}$. Thus, given $F$ increasing, it follows that the transfer either reduces or keeps unchanged the net return of the largest investor. The claim follows.

\section{A.6 Proof of Proposition 5}

We consider the firm's problem with initial capital $W>0$. As stated, suppose $1 / F(x)$ is convex for $x \in[0, X], X>0$, and there exists an optimal scheme guaranteeing investments $\left(x_{n}\right)_{n \in S}$ with $X_{N} \leq X$. We show that an optimal such scheme specifies a permutation $\pi^{*}=\left(n_{1}^{*}, \ldots, n_{N}^{*}\right)$ and returns $\left(r_{i}^{*}, k_{i}^{*}\right)_{i \in S}$ as described in the proposition.

Optimal returns. We begin by showing that an optimal scheme specifies returns $\left(r_{i}^{*}, k_{i}^{*}\right)_{i \in S}$ for some permutation $\pi=\left(n_{1}, \ldots, n_{N}\right)$. Observe that the result in Lemma 1 applies to this setting without change. Hence, any optimal scheme specifies some permutation $\pi=\left(n_{1}, \ldots, n_{N}\right)$ and returns $\left(r_{i}, k_{i}\right)_{i \in S}$ which satisfy, for each $i \in S$ and each $j \in\{i, \ldots, N\}$

$$
r_{i} F\left(W+X_{j}\right)+k_{i}\left(1-F\left(W+X_{j}\right)\right) \geq \theta
$$

Suppose first that $r_{i} \geq k_{i}$ for some $i \in S$. By the arguments in the proof of Proposition 1 , we must then have $r_{i} \geq \theta$ and (24) holding with equality for $j=i$ :

$$
r_{i} F\left(W+X_{i}\right)+k_{i}\left(1-F\left(W+X_{i}\right)\right)=\theta
$$

Suppose next that $r_{i}<k_{i}$ for some $i \in S$. Then analogous arguments now yield $k_{i}>\theta$ and (24) holding with equality for $j=N$ :

$$
r_{i} F\left(W+X_{N}\right)+k_{i}\left(1-F\left(W+X_{N}\right)\right)=\theta
$$

Let us define

$$
\eta_{i} \equiv \frac{1-F\left(W+X_{i}\right)}{F\left(W+X_{i}\right)}
$$


and

$$
\widetilde{\eta}_{i} \equiv\left\{\begin{array}{l}
\eta_{i} \text { if } r_{i} \geq k_{i} \\
\eta_{N} \text { if } r_{i}<k_{i}
\end{array}\right.
$$

Note that by (25) and (26), if $r_{i} \neq k_{i}$, changing $k_{i}$ by $\varepsilon>0$ arbitrarily small and $r_{i}$ by $-\varepsilon \widetilde{\eta}_{i}$ preserves agent $i$ 's incentives.

The following four claims yield that the returns $\left(r_{i}^{*}, k_{i}^{*}\right)_{i \in S}$ described in the proposition are optimal.

Claim 1: There is an optimal scheme satisfying $r_{i}^{*} \geq k_{i}^{*}$ for all $i \in S$.

Proof: Suppose by contradiction that $k_{i}>r_{i}$ for some $i \in S$ in any optimal scheme. Take any such scheme and $i \in S$. By $(24), k_{i}>\theta$, and by $\left(\mathrm{BC}_{W}\right)$ and $(24), k_{j}<\theta<r_{j}$ for some $j \neq i$. Consider a perturbation in which we increase $k_{j}$ by $\varepsilon>0$ arbitrarily small and reduce $r_{j}$ by $\varepsilon \widetilde{\eta}_{j}$, while at the same time reducing $k_{i}$ by $\varepsilon \frac{x_{n_{j}}}{x_{n_{i}}}$ and increasing $r_{i}$ by $\varepsilon \widetilde{\eta}_{i} \frac{x_{n_{j}}}{x_{n_{i}}}$. Note that $\widetilde{\eta}_{i}=\eta_{N}$ and $\widetilde{\eta}_{j}=\eta_{j} \geq \eta_{N}$. The perturbed scheme therefore continues to satisfy the firm's budget constraint $\left(\mathrm{BC}_{W}\right)$ and, by $(25)$ and $(26)$, it preserves the agents' incentives. Moreover, the perturbation changes the firm's expected payoff $V$ by

$$
x_{n_{j}} \varepsilon F\left(W+X_{N}\right)\left(\eta_{j}-\eta_{N}\right)
$$

If we can pick $j<N$, the perturbation strictly increases the firm's expected payoff, contradicting the optimality of the original scheme. So suppose that in the original scheme, $k_{\ell} \geq \theta$ for all $\ell \neq N$. Then we can perform the perturbation for $j=N$ without affecting the firm's expected payoff. Moreover, we can continue performing this perturbation until we obtain $k_{\ell}=\theta=r_{\ell}$ for all $\ell \neq N$. Since the perturbation keeps $\sum_{\ell \in S} k_{\ell} x_{n_{\ell}}$ unchanged and we end up with $\sum_{\ell \neq N} k_{\ell} x_{n_{\ell}}=\theta \sum_{\ell \neq N} x_{n_{\ell}}$, the fact that we must have started with $\sum_{\ell \in S} k_{\ell} x_{n_{\ell}} \leq W<\theta X_{N}$ implies that we end up with $k_{N} x_{n_{N}}<\theta x_{n_{N}}$. Thus, we obtain $k_{N}<\theta<r_{N}$, and this completes the construction of an optimal scheme with $r_{\ell} \geq k_{\ell}$ for all $\ell \in S$.

Claim 2: There is an optimal scheme satisfying $k_{i}^{*} \geq 0$ for all $i \in S$.

Proof: By Claim 1 and (25), there is an optimal scheme satisfying

$$
r_{i}^{*} F\left(W+X_{i}\right)+k_{i}^{*}\left(1-F\left(W+X_{i}\right)\right)=\theta
$$

for all $i \in S$. Claim 2 then follows from analogous arguments to those used in the proof of Proposition 1. 
Claim 3: There is an optimal scheme satisfying $\sum_{i \in S} k_{i}^{*} x_{n_{i}}=W$.

Proof: Suppose by contradiction that $\sum_{i \in S} k_{i} x_{n_{i}}<W$ in any optimal scheme. Take any such scheme. Note that there must exist $j \in S$ with $k_{j}<\theta$. Then consider a perturbation in which we increase $k_{j}$ by $\varepsilon>0$ arbitrarily small and reduce $r_{j}$ by $\varepsilon \eta_{j}$. Since $\sum_{i \in S} k_{i} x_{n_{i}}<W$, the perturbed scheme continues to satisfy the firm's budget constraint $\left(\mathrm{BC}_{W}\right)$, and by (27) it preserves the agents' incentives. Moreover, the perturbation changes the firm's expected payoff $V$ by

$$
x_{n_{j}} \varepsilon \frac{\left(F\left(W+X_{N}\right)-F\left(W+X_{j}\right)\right)}{F\left(W+X_{j}\right)},
$$

which is positive (and strictly positive if $j \in\{1, \ldots, N-1\}$ ). Since we can perform this perturbation until $\sum_{i \in S} k_{i} x_{n_{i}}=W$, we obtain a contradiction, proving the claim.

Claim 4: In any optimal scheme, $k_{i}^{*} \in(0, \theta)$ for at most one agent $n_{i} \in S$.

Proof: Suppose by contradiction that there exists an optimal scheme specifying $k_{i}, k_{j} \in$ $(0, \theta)$ for some $i, j \in S, i \neq j$. Without loss, take $i>j$. Then we can perform a perturbation like the one considered in Claim 1: we increase $k_{j}$ by $\varepsilon>0$ arbitrarily small, reduce $r_{j}$ by $\varepsilon \widetilde{\eta}_{j}$, reduce $k_{i}$ by $\varepsilon \frac{x_{n_{j}}}{x_{n_{i}}}$, and increase $r_{i}$ by $\varepsilon \widetilde{\eta}_{i} \frac{x_{n_{j}}}{x_{n_{i}}}$. Since $\widetilde{\eta}_{j}=\eta_{j}>\eta_{i}=\widetilde{\eta}_{i}$, the perturbation satisfies the firm's budget constraint, preserves the agents' incentives, and strictly increases the firm's expected payoff $V$.

Optimal permutation. Given the characterization of the optimal returns, we next show that the permutation $\pi^{*}=\left(n_{1}^{*}, \ldots, n_{N}^{*}\right)$ described in the proposition is optimal. Consider a scheme specifying some $\pi=\left(n_{1}, \ldots, n_{N}\right)$ and $\left(r_{i}^{*}, k_{i}^{*}\right)_{i \in S}$. Note that for some $i_{W} \in S$, we have $\left(r_{i}^{*}, k_{i}^{*}\right)=\left(\frac{\theta}{F\left(W+X_{i}\right)}, 0\right)$ for all $i<i_{W}$ and $\left(r_{i}^{*}, k_{i}^{*}\right)=(\theta, \theta)$ for all $i>i_{W}$. It then follows from Proposition 2 that an optimal ranking of agents $n_{i}$ for $i<i_{W}$ satisfies

$$
x_{n_{1}} \geq \ldots \geq x_{n_{i_{W}-1}} .
$$

Furthermore, by Proposition 3 and $1 / F(x)$ convex, any mean-preserving spread of the distribution of $\left(x_{n_{i}}\right)_{i<i_{W}}$ lowers the firm's cost. Instead, for agents $n_{i}$ for $i>i_{W}$, neither the ranking of these agents nor the distribution of their capital affects the firm's cost. The reason is that the firm's cost of raising $\left(x_{n_{i}}\right)_{i>i_{W}}$ is simply equal to $\sum_{i>i_{W}} \theta x_{n_{i}}$. Consequently, it follows that it is optimal for the firm to specify a permutation satisfying

$$
x_{n_{1}} \geq \ldots \geq x_{n_{i_{W}-1}} \geq x_{n_{i_{W}+1}} \geq \ldots \geq x_{n_{N}} .
$$


To complete the proof, we next show that an optimal permutation also satisfies $x_{n_{i_{W}-1}} \geq x_{n_{i_{W}}} \geq x_{n_{i_{W}+1}}$. Note that this follows immediately if $i_{W}=1$ or $\sum_{i>i_{W}} \theta x_{n_{i}}=$ $W$. Suppose that neither of these holds. The firm's cost of raising $x_{n_{i_{W}}}$ is equal to

$$
F\left(W+X_{N}\right) x_{n_{i_{W}}} r_{i_{W}}^{*}+\left(1-F\left(W+X_{N}\right)\right) x_{n_{i_{W}}} k_{i_{W}}^{*} .
$$

Substituting with the optimal returns, taking into account that $\min \left\{\theta x_{n_{i_{W}}}, W_{i_{W}}\right\}=$ $W_{i_{W}}$, yields

$$
\left.\frac{F\left(W+X_{N}\right)}{F\left(W+X_{i_{W}}\right)}\left[x_{n_{i_{W}}} \theta-W_{i_{W}}\left(1-F\left(W+X_{i_{W}}\right)\right)\right)\right]+\left(1-F\left(W+X_{N}\right)\right) W_{i_{W}} .
$$

Rearranging terms yields

$$
F\left(W+X_{N}\right) \frac{\theta}{F\left(W+X_{i_{W}}\right)}\left[x_{n_{i_{W}}}-\frac{W_{i_{W}}}{\theta}\right]+\theta \frac{W_{i_{W}}}{\theta} .
$$

This expression shows that the firm's cost of raising $x_{n_{i_{W}}}$ is equal to the cost of paying net returns $\left(r_{i_{W}}, k_{i_{W}}\right)=(\theta, \theta)$ on the portion of capital $W_{i_{W}} / \theta$ and net returns $\left(r_{i_{W}}, k_{i_{W}}\right)=$ $\left(\frac{\theta}{F\left(W+X_{\left.i_{W}\right)}\right.}, 0\right)$ on the remaining portion $x_{n_{i_{W}}}-W_{i_{W}} / \theta$. By Proposition 3 and $1 / F(x)$ convex, it follows that a permutation satisfying $x_{n_{i^{-1}}} \geq x_{n_{i_{W}}} \geq x_{n_{i_{W}+1}}$ is optimal.

\section{References}

Akerlof, Robert and Richard Holden, "Movers and Shakers," Quarterly Journal of Economics, 2016, 131 (4), 1849-1874.

_ and _, "Capital Assembly," 2018. CEPR Discussion Paper 11763.

Andreoni, James, "Toward a Theory of Charitable Fund-Raising," Journal of Political Economy, 1998, 106 (6), 1186-1213.

Bagnoli, Mark and Ted Bergstrom, "Log-Concave Probability and Its Applications," Economic Theory, 2005, 26, 445-69.

Bernstein, Shai and Eyal Winter, "Contracting with Heterogeneous Externalities," American Economic Journal: Microeconomics, 2012, 4, 50-76.

Carroll, Christopher D., "Portfolios of the Rich," 2000. NBER Working Paper No. 7826. 
Clayton, William, "Preferential Treatment and the Rise of Individualized Investing in Private Equity," Virginia Law \& Business Review, 2017, 11 (2), 249-308.

Devetag, Giovanna and Andreas Ortmann, "When and Why? A Critical Survey on Coordination Failure in the Laboratory," Experimental Economics, 2007, 10 (3), $331-344$.

Dyck, Alexander and Lukasz Pomorski, "Investor Scale and Performance in Private Equity Investments," Review of Finance, 2016, 20 (3), 1081-1106.

Eliaz, Kfir and Ran Spiegler, "X-games," Games and Economic Behavior, 2015, 89, 93-100.

Holmström, Bengt, "Moral Hazard in Teams," The Bell Journal of Economics, 1982, 13 (2), 324-340.

Innes, Robert and Richard J. Sexton, "Strategic Buyers and Exclusionary Contracts," American Economic Review, 1994, 84 (3), 566-584.

Inostroza, Nicolas and Alessandro Pavan, "Persuasion in Global Games with Application to Stress Testing," 2018. Working paper.

Lazear, Edward P. and Sherwin Rosen, "Rank-Order Tournaments as Optimum Labor Contracts," Journal of Political Economy, 1981, 89 (5), 841-864.

Rasmusen, Eric B., J. Mark Ramseyer, and John S. Wiley Jr., "Naked Exclusion," American Economic Review, 1991, 81, 1137-45.

Rey, Patrick and Jean Tirole, "Financing and Access in Cooperatives," International Journal of Industrial Organization, 2007, 25, 1061-1088.

Rosen, Sherwin, "The Economics of Superstars," American Economic Review, 1981, 71 (5), 845-858.

Rothschild, Michael and Joseph E. Stiglitz, "Increasing Risk: I. A Definition," Journal of Economic Theory, 1970, 2, 225-243.

Sákovics, József and Jakub Steiner, "Who Matters in Coordination Problems?," American Economic Review, 2012, 102 (7), 3439-3461.

Segal, Ilya R., "Contracting with Externalities," Quarterly Journal of Economics, 1999, 114, 337-388. 
_, "Coordination and Discrimination in Contracting with Externalities: Divide and Conquer?," Journal of Economic Theory, 2003, 113, 147-81.

- and Michael D. Whinston, "Naked Exclusion: Comment," American Economic Review, 2000, 90, 296-309.

Tan, Wen, "All LPs Are Equal (...But Some Are More Equal than Others)," 2016. Aberdeen Standard Investments, http://www . aberdeen-asset.it/en/thinkingaloud/ investment-clarity/all-lps-are-equal-but-some-are-more-equal-than.

Winter, Eyal, "Incentives and Discrimination," American Economic Review, 2004, 94, $764-773$. 